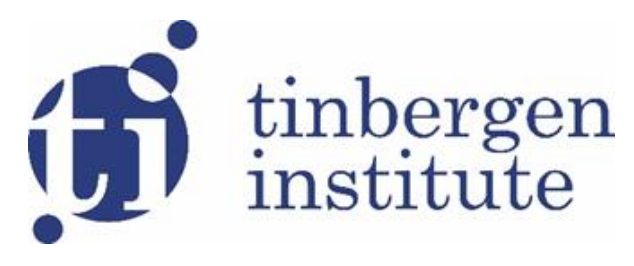

TI 2018-055/V

Tinbergen Institute Discussion Paper

\title{
Mobile Phones and Mozambique Farmers: Less Asymmetric Information and More Trader Competition?
}

Revision: March 2022

Wouter Zant ${ }^{1}$ 
Tinbergen Institute is the graduate school and research institute in economics of Erasmus University Rotterdam, the University of Amsterdam and Vrije Universiteit Amsterdam.

Contact: discussionpapers@tinbergen.nl

More TI discussion papers can be downloaded at https://www.tinbergen.nl

Tinbergen Institute has two locations:

Tinbergen Institute Amsterdam

Gustav Mahlerplein 117

1082 MS Amsterdam

The Netherlands

Tel.: + 31(0)205984580

Tinbergen Institute Rotterdam

Burg. Oudlaan 50

3062 PA Rotterdam

The Netherlands

Tel.: +31(0)10408 8900 


\title{
Mobile Phones and Mozambique Farmers:
}

\section{Less Asymmetric Information and More Trader Competition?}

\author{
Wouter Zant*
}

\begin{abstract}
We measure how the introduction of mobile phones in Mozambique affected unit values of household maize sales, maize producer prices and traders' margins. Our estimations are based both on representative household surveys for the years 2002, 2003, 2005, 2006 and 2008, and on weekly producer and market prices of white maize grain from July 1997 to December 2009 for 15 major producer markets. We find household sales unit values and producer price decreases, and traders' margin increases between $14 \%$ and $22 \%$, indicating benefits for traders. Our results are robust to various threats. We investigate heterogeneity of impacts in order to explore underlying causes: impacts on margins decrease with competitiveness and increase with gains from long-distance trade. Impacts on household selling prices are not significantly correlated with educational attainment, but the fall in prices is much less with larger household wealth. Impacts on household selling prices and producer prices also become less negative over time, suggesting delayed adoption by farmers.
\end{abstract}

JEL code: O13, O33, Q11, Q13, G14; Key words: search costs, asymmetric information, mobile phones, agricultural markets, maize prices, Mozambique, sub-Sahara Africa

\footnotetext{
* Wouter Zant is associate professor at the Vrije Universiteit and research fellow of the Tinbergen Institute, both Amsterdam, the Netherlands; mailing address: Wouter Zant, Vrije Universiteit, De Boelelaan 1105, room 10A79, 1081 HV Amsterdam, The Netherlands; email: wouter.zant@vu.nl; tel: +31 20598 9592; I would like to thank two anonymous reviewers of this journal for useful suggestions and comments. I am also grateful to Jasper Dekkers for constructing maps, to Hans Quené and Benedito Cunguara for compiling and interpreting the survey data, and to Jenny Aker, Peter Lanjouw and Menno Pradhan for helpful feedback. All errors are my own.
} 


\section{Introduction}

Information on market prices is essential for transactions in agricultural commodity chains. Changes in information infrastructure will affect the behavior of agents operating in these chains, like farmers in sub-Saharan Africa who sell their output to local traders. How will the introduction of mobile phones - a change in information infrastructure - affect farmer-trader bargaining? Farmers' information base - traditionally past transactions, price offers by other traders, or formal sources like radio and price bulletins - is typically imperfect, particularly visà-vis traders, leading to asymmetric information in bargaining (Stigler, 1961; Akerlof, 1970). The introduction of mobile phones - offering access to accurate and instantaneous information at low cost - reduces asymmetric information, improves farmers' bargaining position and will increase prices paid to farmers (Courtois and Subervie, 2015). Is the change in asymmetric information strong enough to lead to increased prices paid to farmers? Overall empirical evidence is mixed on the potential benefits of mobile phones for farmers: some studies find positive effects on prices paid to farmers (Jensen, 2007; Svensson and Yanagizawa, 2009; Nakasone, 2013; Courtois and Subervie, 2015), while others find no effect (Fafchamps and Minten, 2012; Tadesse and Bahiigwa, 2015; Aker and Skoll, 2016). Empirical work does offer support for a variety of other farmers' benefits of mobile phones, internet access and internet sources: prevention of waste, inefficiency and spoilage of perishable crops (Jensen, 2007; Muto and Yamano, 2009); increased market participation in remote areas (Muto and Yamano, 2009), crop diversification (Aker and Skoll, 2016) and crop area increases (Goyal, 2010). However, some studies report no impacts on marketing (Tadesse and Bahiigwa, 2015), and on value added, crop losses, crop choices and cultivation practices (Fafchamps and Minten, 2012). Occasionally, farmers' benefits represent improved efficiencies in the marketing chain that flow to producers, rather than increased prices or cultivation related improvements (Jensen, 2007; Goyal, 2010). 
For traders the introduction of mobile phones brings different changes: it reduces search costs (Jensen, 2010). Search costs arise from collecting information on prices in different markets, and from collecting information on costs associated with different trade opportunities, typically by traveling across agricultural areas. Mobile phones reduce traders' search costs, as the collection of information on prices and trade costs is simplified, cheaper and less time consuming. On top of the reduction in search costs, mobile phones improve the content of traders' information. It helps to better assess source and destination markets, to enhance the quality of networks, to find lower cost sources and opportunities and to make a better selection of profitable transactions. How the reduction in search costs and improvement in information quality for traders jointly interacts with the reduced asymmetric information for farmers is not often investigated empirically. Empirical evidence on the impact of mobile phones on the traders' business has focused on impacts higher up in the marketing chain, on price dispersion across producer and consumer markets, pass-through to terminal markets and market efficiency (Aker, 2010; Aker and Fafchamps, 2015; Zant 2019, 2021). A major question in this work is whether reductions in search costs are captured by traders or passed through to others. Aker (2010) finds increased market efficiency and Zant (2019) finds benefits for consumers. In both cases farmers vis-à-vis traders, and across markets, traders vis-à-vis consumers - the distribution of benefits of cost reductions depend critically on the degree of competitiveness among traders. Empirical evidence on the degree of competition is also mixed: Dillon and Dambro (2017) conclude, on the basis of an extensive review of empirical studies on sub-Sahara Africa that the evidence is 'broadly supportive' of the notion that crop markets are competitive. Others, however, find clear support for non-competitive behavior by traders (Atkin and Donaldson, 2015; Bergquist and Dinerstein, 2020; Zant 2021).

What will be the impact of mobile phones on farmers and traders with the various mechanisms at work? In the current study we investigate how the introduction and rollout of 
the mobile phone network in Mozambique affects prices for maize farmers and margins for maize traders. We develop a simple framework that explains several responses to the introduction of mobile phones, both under competitive and non-competitive conditions. For the empirical work we use both household survey data for the years 2002, 2003, 2005, 2006, 2008 and a panel of weekly producer and market prices of white maize grain, from July 1997 to December 2009, for 15 major producer markets, and combine both types of data with data on the rollout of the mobile phone network. We find that traders' margins increase and household sales unit values / producer prices decrease by $14 \%$ to $22 \%$. The results point to noncompetitive trader behavior. We further investigate heterogeneity. Impacts are shown to decrease with competitiveness. Markets with high population density and embedded in a dense network of cities and towns even support increases in household sales unit values / producer prices: under these circumstance the new information technology benefits farmers. Margins are also correlated with terminal market prices in urban areas. Negative impacts on household selling prices are shown to decrease with household wealth, but do not correlate with educational attainment.

Our paper makes two contributions. First, analysis of the impact of mobile phones is either exclusively household survey based empirical work focusing on farmers (Muto and Yamano, 2009; Fafchamps and Minten, 2012; Tadesse and Bahiigwa, 2015) or exclusively market based work focusing on traders (Aker, 2010; Aker and Fafchamps, 2014; Zant, 2019). Our work explores impacts along the marketing chain, jointly and simultaneously on farmers and traders, exploiting both household survey data and market price data. Secondly, among researchers there is a belief that mobile phones are beneficial to farmers as these resolve asymmetric information in farmer-trader bargaining. Our framework and empirical estimations show the combined impact of improved information for farmers and traders under varying 
degrees of competition among traders, and thereby admits a larger set of outcomes, including both price increases and price decreases for farmers.

The rest of this paper is organized as follows. In Section 1 we describe the Mozambique maize market and mobile phone rollout. In Section 2 we outline the conceptual framework. In Section 3 we formulate our empirical strategy. In Section 4 we document the data. In Section 5 we present empirical estimates and robustness checks. We summarize our results in Section 6.

\section{Maize, Domestic Trade, Information and Mobile Phone Rollout in Mozambique}

\section{Maize production and maize prices}

Maize is the most important staple food of Mozambique: of all crops grown it is the most widely produced, marketed, exported and consumed. On the consumption side the calorie share of maize in the Mozambique diet ranges from 25\% to $39 \%$, corresponding to per capita consumption of 60 to $85 \mathrm{~kg}$ per year, with lower shares in the Maputo region due to substitution with rice (Tschirley et al., 2006). Growing maize is widespread throughout the country. Household survey data show that nearly all households grow maize (Appendix, Table A6): the share of households growing maize by province is above $80 \%$ for most provinces, well above $90 \%$ in many provinces and only slightly lower in Nampula (around 65\%) and Zambezia (around 73\%). Agricultural production in Mozambique is rain-fed. Because of better rainfall distribution and soil fertility in the North, and unfavorable weather conditions and occasional pests in the South (Abdula, 2005; and Appendix, Figure A3), production of maize is concentrated in the central and northern part of Mozambique (for a map of Mozambique: Appendix, Figure A1). Occasional droughts, flooding and related devastation of crops cause major drops in production, and hikes in prices (Abdula, 2005). Selling maize on the market rather than using maize for home consumption - is much less prevalent than growing maize. Only $15 \%$ to $25 \%$ of all maize growing households sell maize grain, with substantial variation 
by province (Appendix, Table A7). Nevertheless, maize is three times more marketed than cassava, and households spend about as much on maize as they do on all other staple foods combined (Tschirley et al., 2006). More than 50\% of households sell their maize grain to itinerant traders, while only $15 \%$ of households sell to a client on the market (Appendix, Table A8). Also, $82 \%$ of households sell their maize in their home village, rather than in the nearby town or city. Apparently constraints to sell on the market are binding for most farmers.

Price evolution over the years reflects the rain-fed character of agriculture, with large price peaks in 2002 and 2006 due to droughts ${ }^{1}$ (Appendix, Figure A4). Maize planting starts in November, with the key rains from December to March, which creates an additional strong and regular seasonality in maize prices. Prices rise gradually from July-August, reach a maximum around February-March, and drop sharply from April to June, when the new harvest arrives. The degree of price variation over the season is large, with lean season prices twice as high as prices in post-harvest months (Appendix, Figure A5), but common to seasonality in staple food prices observed in sub-Saharan countries (Kaminski et al., 2016) ${ }^{2}$. Liquidity constrained farmers follow a similar seasonality and sell maize systematically more during the months after harvest (Appendix, Figure A9). Margins - market prices minus producer prices, the source of income of local traders - averaged over markets oscillate with large variations around a mean of approximately 20\% (Appendix, Figure A6). Margins by market, averaged over time, are an order of magnitude different across markets (Appendix, Figure A7), reflecting local circumstances like the distance from the market to the nearby producer areas, the geographical dispersion of farmers, the number of traders and the degree of competition between traders.

\footnotetext{
${ }^{1}$ The 2009 peak was triggered by a surge in food prices world-wide, which was due to high energy prices, regional droughts in producing areas, WTO, and shifts to trade in commodities in the aftermath of the financial crisis. ${ }^{2}$ Under these circumstances transaction timing is critical for farmers: postponing maize sales by two months could increase proceeds by $20 \%$ to $30 \%$. Improved information on market prices may therefore also affect storage behavior by farmers (Burke et al., 2018; Aggarwal et al., 2018).
} 


\section{Domestic trade in sub-Sahara Africa}

What are the stylized facts of local trade in sub-Sahara Africa (SSA)? Several studies explore the SSA domestic trading business (Minten and Kyle, 1999; Fafchamps et al., 2005; Jacoby and Minten, 2009; de Vletter and Polana, 2001; Fafchamps and Vargas Hill, 2005; Sitko and Jayne, 2014). Fafchamps et al. (2005), using trader surveys for Benin, Madagascar and Malawi, highlight several characteristics: the size distribution of trader businesses and the prevalence of many small scale businesses suggest constant returns to scale in trade; around $75 \%$ of traders buy directly from farmers and sell as a retailer; the largest cost of domestic trade is transport (48 to $57 \%$ of total transaction costs); and average distance between purchase location and sale location of maize transactions is around $55 \mathrm{~km}$ with a maximum of $200 \mathrm{~km}$. The average (median) number of days between purchase and sale is close to eight days (three days), with around $45 \%$ of transactions completed within two days and less than $10 \%$ taking more than 14 days (Fafchamps et al., 2005). The trading business is nearly completely self-funded (Vletter and Polana, 2001; Fafchamps et al., 2005). Small-scale itinerant traders in Mozambique carry out most marketing functions themselves: apart from supplying their own working capital, they also hire storage facilities and arrange truck transport (De Vletter and Polana, 2001). Sitko and Jayne (2014) find that most maize sales by farmers in Malawi, Kenya, Zambia and Mozambique are sales at the farm-gate, through itinerant traders. In Mozambique close to $60 \%$ of all farmers' sales are at the farmgate through itinerant traders (also de Vletter and Polana, 2001). The large proportion of sales at the farm-gate has several backgrounds. Traders visit villages to collect maize, while many smallholder farmers have insufficient maize production to make transport to the market profitable. Unlike alternative buyers traders pay cash at the time of sale and enter markets soon after harvest to collect grain, which is attractive for liquidity constrained farmers. Close to $30 \%$ of villages have less than 10 traders visiting after harvesting and more than $75 \%$ of sales takes place within $5 \mathrm{~km}$ of the farm-gate (Sitko and Jayne, 2014). 


\section{Information for farmers and traders}

How do farmers and traders inform themselves about prices? And how has access to information and information dissemination developed over time? A key institution is Sistema de Informação de Mercados Agrícolas de Moçambique (SIMA; www.masa.gov.mz/sima). SIMA, which started as a USAID / Michigan State University funded initiative, distributes weekly price bulletins by email (Quente-Quente), amongst others to farmer organizations and traders, through SIMA's provincial offices (which further reproduce and disseminate information), through the Ministry of Commerce that uses the information in their own bulletins, and through broadcasts on the national radio and television news (to whom SIMA contractually offers weekly input to market programs). Traders' interviews confirm the usefulness of the SIMA price information ${ }^{3}$. Despite the systematic distribution and availability of price information through SIMA, personal and professional contacts are the key information channel for domestic traders in Mozambique domestic trade, and, in fact, throughout most SSA. Since mobile phones drastically facilitate the exchange of information in traders' network, the introduction of mobile phones is likely to change the distribution of costs or prices and have an impact on prices paid to farmers.

\section{Mobile phone rollout}

Similar to most other sub-Saharan countries (ITU, 2016), mobile phone technology was introduced in Mozambique at the end of the 1990s and early 2000s. The number of mobile phone subscriptions in Mozambique increased from 51,065 in 2000 to 7,224,176 in 2010 (ITU, 2016), corresponding to an increase in the share of the population with a mobile phone from $0.3 \%$ in 2000 to $30.1 \%$ by 2010 . These numbers compare to land line coverage of less than 0.4\% (fixed telephone subscriptions in 2010: 88,062). The rollout of the mobile phone network

\footnotetext{
3 “In Mozambique, Market Information publishes its $500^{\text {th }}$ weekly bulletin, a Cause for Celebration", February 2006 (www.masa.gov.mz/sima/).
} 
in Mozambique started in 1997. During the first three years (1997-1999) mobile phone operators exclusively installed mobile phone towers in the densely populated, high income Maputo and Matola area. However, after a period of around ten years the network has extended to most major cities and towns, roughly following the existing trunk road network (Appendix, Figure A2). Roll-out data also reveal that rural areas in general, and the province of Niassa in the north in particular, are underserved, both in terms of area and population.

\section{Conceptual Framework: Transactions between Farmers and Traders}

In order to capture the key segments of the agricultural trading business and position the empirical work, we distinguish local trade from long-distance trade. Local traders are based in major towns in a producer areas, exclusively operate in the area surrounding this town, of which they maintain a network of farmers' contacts. After harvest they travel around with a small pick-up truck, using their farmers' contacts to purchase maize at producer prices, and, in this way, collect and aggregate modest quantities of maize $(<500 \mathrm{~kg})$. The purchased maize is transported to the market of the nearby major town and sold at market prices to whoever is interested, either final consumer, processor, wholesale trader or long-distance trader. In practice this trade is implemented by liquidity constrained traders with limited working capital: transactions take place within narrow time slots of less than a few days, and within short transport distances of $50 \mathrm{~km}$ at most. Gross income of traders is determined by the price difference between the price paid to farmers and the price received on the market of the major town, and the volume of maize traded.

In contrast with local trade, long-distance trade is trade across rural excess-supply producer markets and, mostly urban, consumer markets. Long-distance trade entails transport over distances between around $200 \mathrm{~km}$ to $2000 \mathrm{~km}$, using large capacity trucks that carry loads of several tons, and taking up to a few weeks (including collection of maize and travelling). 
Research on this type of trade considers spatial price differences, the price differences across producer and consumer markets, the pass-through of prices to terminal markets and the efficiency of the total market (Aker, 2010; Aker and Fafchamps, 2015; Zant 2019, 2021).

The topic of the current study is local trade. The difference between market prices in producer markets and price paid to farmers reflects the gross traders' margin and drives operations of local traders. A key element of this trade is farmer-trader bargaining. Typical farmer-trader bargaining in rural areas takes place at the farm-gate on a one-on-one basis with sequential exposure to different traders, rather than through an ideal line-up of multiple and simultaneous trader offers. Most itinerant traders operate in geographically segmented areas, with varying number of traders servicing dispersed villages and towns. While traders know market prices, benefit from keeping farmers uninformed and exaggerate costs, farmers commonly only have an indication about actual market prices through a variety of not fully accurate and up-to-date information channels.

We investigate the behavior of traders and farmers and evaluate changes in traders' margins and farm gate prices that occur after a change in the information infrastructure. Rather than setting out a fully-fledged model we explain the intuition of the impact of this change on the basis of profits of traders and returns of farmers. Profits of an individual local trader is the sum of profits made on each transaction, and for each product. A sufficiently general formalization of profits of an individual trader runs as follows:

$$
E(\Pi)=\sum_{n} \sum_{k}\left(\Pi_{n k}\right)
$$

where $E$ is the expectation operator, $\Pi$ represents trader profit, $k$ indicates products and $n$ the number of trade transactions. We narrow down to per unit profit of a specific transaction of one specific product: omitting subscripts for number of transactions $(n)$ and product $(k)$, the following expression applies:

$$
E(\pi)=E\left(p_{m t}-p_{f s}\right)-\tau,
$$


where $\pi$ is per unit profit, $p$ is the price of the traded commodity, $m$ and $f$ are geographical markets, $t$ and $s$ are points in time, and $\tau$ are transaction costs. The expression incorporates the trader's main activities, namely spatial arbitrage $(m \neq f)$ and intertemporal arbitrage $(t \neq s)$, or combinations of these activities. Transaction costs $(\tau)$ cover all costs associated with realizing a trade transaction. Transaction costs associated with spatial arbitrage are typically transport costs, and costs associated with intertemporal arbitrage are typically storage and interest costs. Traders incur search costs for both types of arbitrage. We focus in this study exclusively on spatial arbitrage rather than intertemporal arbitrage. Due to a variety of constraints - e.g. limited working capital, lack of credit, storage constraints and risks - spatial arbitrage is dominant in SSA domestic trade (Fafchamps et al., 2005). Hence, we simplify the profit equation into

$$
E(\pi)=E\left(p_{m}-p_{f}\right)-\tau
$$

To further align our framework with the empirical set-up in this study, we incorporate that market prices in markets where local traders sell are known to traders. Conversely, prices at source, the prices paid to farmers, are an uncertain outcome of bargaining with farmers and the degree of competition among traders on the purchasing side. Hence, we have

$$
E(\pi)=p_{m}-E\left(p_{f}\right)-\tau
$$

Farmers, earn income form cultivating a variety of crops: their income per unit of production for a specific crop is given by the price received minus the per unit cultivation costs,

$$
E(\zeta)=E\left(p_{f}\right)-c
$$

where $\zeta$ is the return per unit of production of a specific crop, and $p_{f}$ and $c$ are the price farmers receive from traders and per unit cultivation cost. In bargaining with itinerant traders farmers evaluate $E\left(p_{f}\right)=E\left(p_{m}-\tau\right)$, against the background of their own reservation price $\left(p_{f}>c\right)$ and their own transaction costs of selling merchandise to the market $\left(p_{f}>E\left(p_{m}\right)-\tau^{\text {farmer }}\right)$. 
Since most farmers in Mozambique sell at the farm-gate to itinerant traders (Sitko and Jayne, 2014; Table A8), we adopt the stylized fact that traders have a cost advantage in bringing merchandise to the market ( $\tau^{\text {farmer }}>\tau^{\text {trader }}$ and $\tau=\tau^{\text {trader }}$ ). In the standard empirical setting farmers face an asymmetric information problem when bargaining with itinerant traders: unlike traders farmers are not accurately informed about market prices (Courtois and Subervie, 2015). This asymmetric information problem leads to unfavorable outcomes for farmers.

Introducing a new information infrastructure will impact both on traders and farmers through several channels. The introduction of mobile phones will reduce search costs for traders. Search costs are the time (opportunity cost) and money (explicit search costs) that traders spend in trying to find attractive deals with farmers that offer merchandise. In terms of the trader profit and farmer return expression, search costs are part of transaction costs $(\tau)$, and, hence, a drop in transaction costs will occur. Next, the content and quality of information for traders improve. Apart from a variety of efficiency increases - improved exploitation of network contacts, streamlining of travel, optimizing collection, advance transactions - mobile phones help traders to realize lower purchase prices, because of a better overview of potential supply from farmers. Finally, assuming a quicker take-up of mobile phones by traders vis-àvis farmers ${ }^{4}$, the degree of asymmetric information will increase and strengthen the bargaining position of traders further, creating an additional downward pressure of producer prices.

Conversely, if both farmers and traders have adopted the new information technology, farmers will be able to obtain more accurate and up-to-date information on prices on the nearby local market $\left(p_{m}\right)$, whenever a trader shows up at the farm-gate. Farmers will reject offers

\footnotetext{
${ }^{4}$ Since traders have a stronger market orientation, a higher frequency and intensity of communication with other traders and more eagerness to adopt new technologies relative to farmers, a quicker adoption of traders is a plausible assumption, and also confirmed in related work (e.g. Aker and Fafchamps, 2015)
} 
lower than $p_{f}=p_{m}-\hat{\tau}$, where $\hat{\tau}$ is the farmer's estimate of reasonable traders' costs to transport the merchandise to the nearby local market. This reflects the change from the classic asymmetric to full information bargaining (Courtois and Subervie, 2015).

Perfect competition among traders implies that trader profits are zero $(E(\pi)=0)$ and trader margins exactly reflect transaction costs $\left(p_{m}-E\left(p_{f}\right)=\tau\right)$. Under these conditions cost reductions for traders are fully passed through to farmers: if an individual trader attempts to increase profits, competing traders will step in and offer higher prices to farmers that exhaust the cost reduction. Even without change in the farmer's bargaining position, the new information technology unambiguously increases prices paid to farmers. This also applies if the cost reduction extends the geographical domain of traders and triggers increased trade and a higher trading volume. Free entry into the trading business guarantees that new traders step in and operate under the same conditions as existing traders. Again, and hence also with geographical expansion and increases in trade volume, the new information technology and the related cost reductions for traders are fully passed through to farmers, who see prices paid by traders increase.

Under non-competitive conditions among traders several outcomes are possible, which have in common that the introduction of the new information technology leads to positive trader benefits and, in some cases, reduced producer prices. At the start, prices paid to farmers may remain unaffected: the drop in search costs increases traders' profit (equation (4)) and traders simply cash the extra income. However, the increase in trader profit may be further amplified if traders succeed - helped by the new information technology - in finding lower priced supply from farmers. Under these conditions producer prices will decrease. Also, in the short run, traders experience an improvement in their bargaining position vis-à-vis farmers, because of an expected quicker take-up by traders, which further depresses prices paid to farmers. In the longer run, however, the new information technology increases the information 
base of farmers and resolves the information asymmetry between farmers and traders. This will help farmers to realize higher prices for their output when bargaining with itinerant traders. It is unclear if the last mechanism ( $p_{f}$ increases) offsets the previous mechanisms ( $p_{f}$ decreases): under these conditions the impact on producer prices is not determined and needs to be estimated empirically.

Traders' profits are zero under perfect competition among traders. In practice, the extent of competition among traders varies geographically, with competition decreasing the farther away from locations with busy economic activity. Moreover, geographically more remote and dispersed farmers have a worse information base relative to the farmers in the existing trade domain, a slower take-up of the new information technology and thereby less bargaining power. For these reasons traders, faced with a reduction in search costs, may have an incentive to extend their operations geographically, expanding activities to more remote and less competitive areas. Extending operations to remote areas is likely to lead to lower purchase prices but simultaneously means incurring higher transport costs. Under these conditions, producer prices decrease, transaction costs will decrease less (because of increases in transport costs) and trading activities and market participation of farmers in remote areas increase. If the catchment area of traders increases is also investigated empirically.

To summarize, we expect increases in producer prices due to the introduction of a new information technology under perfect competition among traders. Also if there is a quick takeup of the new technology by farmers and quick learning among farmers on accessing and processing information, producer prices may increase. In most other non-competitive conditions one expects a decrease in producer prices (or no change). We can investigate 
empirically if competitive conditions are supported by the data ${ }^{5}$. We can also explore empirically if traders have shifted their purchases to more remote areas.

\section{Empirical Strategy}

\section{Estimations with market price data}

In order to compare markets with and without mobile phone coverage, we estimate the following specification using OLS:

$$
y_{j t}=\beta_{0}+\beta_{1} \text { mobile }_{\text {phone }}{ }_{j t}+\boldsymbol{X}_{j t} \gamma+\eta_{j}+\theta_{t}+\varphi_{j m}+\varepsilon_{j t},
$$

where $y_{j t}$ is either margin, producer price or market price in market $j$ and period $t$, mobile $_{\text {phone }}{ }_{j t}$ is a binary variable equal to 1 in period $t$ if market $j$ falls within the coverage area of a mobile phone tower, and zero otherwise. The intervention variable is defined as the presence of a mobile phone tower, not mobile phone adoption. We assume that once a market has mobile phone coverage, traders and farmers have access to this information technology. A market with mobile phone coverage is a market within a radius of $35 \mathrm{~km}$ of a mobile phone tower. The vector $\boldsymbol{X}_{j t}$ represents variables that influence margins and prices, such as variations in supply conditions like drought and flooding and variations in demand like population size and income. Since our data are observational rather than experimental, including covariates could be important. The parameters $\eta_{j}$ and $\theta_{t}$ represent market and time fixed effects, $\varphi_{j m}$ represents seasonality in market $j$, and takes the value 1 for each month $m$ (January, February, etc.) and zero elsewhere, and $\varepsilon_{j t}$ is an error term with zero mean and constant variance. Since we have included time and market fixed effects, estimating equation (1) is equivalent to a two-

\footnotetext{
${ }^{5}$ To investigate specific forms of competition like perfect collusion, or Cournot or Bertrand competition, is beyond the scope of this work. Such an investigation requires more shocks and richer micro data on traders and farmers than our core data (like transaction prices and quantities, number of traders, traders' and farmers' characteristics, markets and networks). Various studies have made steps in this direction (Casaburi et al., 2013; Casaburi and Reed, 2016; Falcao Bergquist and Dinerstein, 2020).
} 
way fixed effect difference-in-difference estimation (TWFE-DiD). The parameter of interest is $\beta_{1}$, which measures the impact of mobile phone coverage on either price margins, producer prices or market prices. All variables other than indicator variables are in natural logarithms, which allows us to interpret coefficients as elasticities. Following standard practice we present robust standard errors clustered by market - the unit of intervention assignment - in the reported estimations (Bertrand et al., 2004). The identifying assumption in the DiD estimation requires that trends in outcomes are the same for both treated and untreated observations, and that there are no spillovers between treated and non-treated units. Both assumptions are addressed in the empirical section.

\section{Estimations with household survey data}

Along with the price based estimation results, we estimate the impact of mobile phones on household selling prices (or unit values) using household survey data. For the price-based estimation results to be convincing, producer price results based on market data should be similar to those of household selling prices from household survey data. We estimate a specification that comes close to the relationship estimated with market data:

$$
\text { household selling price }_{h t}=\beta_{0}+\beta_{1} \text { mobile phone }_{j t}+\eta_{n} * \omega_{t}+\psi_{k}+\varepsilon_{h t} \text {, }
$$

where $\eta_{n} x \omega_{t}$ is the interaction of province ${ }^{6}$ and survey year, capturing between-year seasonal and region fixed effects; and $\psi_{k}$ represent location fixed effects where locations are primary sampling units (PSUs), equivalent to villages and communities. The estimated relationship is not a genuine DiD estimation since the TIA surveys are not a panel of households. Including a 'primary sampling unit' fixed effect is as close as we can get to estimating a DiD. The interaction of province and year accounts for joint seasonal and regional variation of prices,

\footnotetext{
${ }^{6}$ We exploit three geographical variables in the TIA surveys, originating from the administrative division of Mozambique: provinces (10), districts (138) and primary sampling units (>900).
} 
largely due to between-year-and-province variations in weather and rainfall ${ }^{7}$, and fluctuations of the general price level.

As in the case of market price data, the intervention variable (mobile phone) is defined as households falling within the coverage area of a mobile phone tower, i.e. less than $35 \mathrm{~km}$ away from a mobile phone tower (sample A). Unfortunately not all households have location coordinates. In order to increase the number observations for estimation, we make a few assumptions on geography and mobile phone coverage. First, we include to the sample all households in a Primary Sampling Unit (village, community) if location coordinates are available for at least one household in the PSU (sample B). Next, we assume that households have mobile phone coverage if at least one household in the primary sampling unit has mobile phone coverage. Since adoption and use of mobile phones spreads easily within villages, we consider this extension of mobile phone coverage observations potentially plausible ${ }^{8}$. Secondly, and likewise, we add to the (adjusted) sample all households in a district if location coordinates are available for at least one household in the district (sample C). For this sample we assume that households have mobile phone coverage if district means of mobile phone coverage are 0.5 or higher. We deliberately constructed this extension of observations to exhaust all available price observations. Unlike sample B, we acknowledge that within district spread of adoption and use of mobile phones is far from self-evident given the area size of districts. Nevertheless, shares of observations with and without coverage over the years are very similar (Table A5). The share of sample observations in total household selling price observations increases from $44.0 \%$ for sample A, to $63.4 \%$ for sample B to $100 \%$ for sample

\footnotetext{
${ }^{7}$ Since household farm-gate prices are not recorded by date, we cannot control for within year seasonality.

${ }^{8}$ The strategy to increase the number of observations for estimation may appear a crude approximation, especially since it defies research on village level networks: however, note that the missing observations due to missing household location coordinates may also entail selection bias.
} 
$\mathrm{C}$ (Table A5 in the Appendix summarizes total observations, sub-samples and mobile phone coverage by year).

\section{Investigating heterogeneity in impacts}

The next question is what is driving our estimated impacts. We investigate potential causes by interacting the impact variable with variables that are potentially correlated with impact on farmers, or impact on traders. We employ the following specifications for the market based price data:

$$
\operatorname{margin}_{j t}=\beta_{0}+\sum\left[\beta_{1}\left(Z_{j t} * \text { mobile phone } j t\right)\right]+\eta_{j}+\theta_{t}+\varphi_{j m}+\varepsilon_{j t}
$$

and for the household survey data:

$$
\begin{aligned}
& \text { household selling price }_{h t}= \\
& \qquad \beta_{0}+\sum\left[\beta _ { 1 } \left(Z_{h t} *\right.\right. \text { mobile phone } \\
& h t)]+\eta_{n} * \omega_{t}+\psi_{k}+\varepsilon_{h t},
\end{aligned}
$$

where $Z$ is a variable with which the impact of mobile phone coverage is potentially correlated. For the specification of the $\mathrm{Z}$ variables we first look at the margin equation (equation (8)), the equation that reflects the traders' response. What factors drive the impact of mobile phones on traders' margins? We consider two factors: competition and terminal market prices. Following the conceptual framework, the degree of competition between traders - which plausibly varies between markets - likely affects impact on traders' margins. We approximate the degree of competition with population density and network density. Markets which are integrated in a dense network of nearby markets and towns, with high population densities and high levels of economic activity, are likely to be more competitive than isolated, far-away markets in remote areas. At the same time, isolated markets in remote areas, far from economic centers, with low population density and less competitive, may be 'opened up' with the help of mobile phones, i.e. with the help of traders, who are attracted by non-competitive conditions ${ }^{9}$. We conjecture

\footnotetext{
${ }^{9}$ We emphasize that our approximations of competition are only rough indications with a rather broad coverage. Network and population density captures competition between local traders but also many features of markets
} 
that a high population density or a high network density is correlated with a small or even negative impact on margins, while the opposite logic applies in the case of low densities.

Market prices in far-away terminal markets are another factor that drive the impact of mobile phones on traders' margins. Mobile phones also offer improved information on terminal market prices and on country-wide imbalances, and thereby also improve the bargaining position of local traders vis-à-vis long-distance traders. These terminal market prices reflect final demand, and potentially also drive intermediate demand. Hence, we explore if the impact of mobile phones on the local trader margin is correlated with the price difference between local source markets in rural areas and terminal markets in urban areas. We use terminal market prices in Maputo and Nampula, the largest cities in the south and in the north. If the mobile phone impact on the 'within market' margin between market and producer prices is driven by price differences with terminal markets, we expect a positive impact which is higher in the case of larger price differences.

Next, we investigate heterogeneity in the household selling price equation (equation (9)), the equation that reflects farmers' responses. We propose two channels that affect the impact of mobile phones on farmers' sales prices: wealth and educational attainment. Many farmer households are poor, liquidity constrained and opportunity constrained. Few farmer households engage in market sales due to limited production (no surplus output) on small holdings (Appendix, Table A10); few households have sufficient production to consider storage, sufficient savings to delay sales or sufficient wealth to afford storage capacity (Appendix, Table A11). Potential benefits from delaying sales are, however, large (Appendix, Figure A5). The timing of sales is concentrated in a few months after harvest (Appendix, Figure

other than competition (amongst other things it reflects the demand side). Moreover, even with high network and population densities, and a large number of traders collusion is possible (Falcao Bergquist and Dinerstein, 2020). 
A8 and A9) reflecting liquidity constraints ${ }^{10}$. The large share of sales at the farm-gate (Appendix, Table A8), either to itinerant traders or to neighbors, also suggests a lack of opportunities to transport output to more profitable markets because of high transport costs and insufficient scale. In short, both intertemporal and spatial arbitrage by farmers is constrained. If farmers lack the funds and equipment to transport their maize to nearby markets, it is impossible to benefit from (higher) market prices, which itself removes the credible threat of selling in the market and weakens the bargaining position of farmers. Under these conditions access to mobile phones may improve information for all farmers, but will possibly only improve the bargaining position of wealthy farmers, and increase their realized farm-gate prices or mitigate the negative impact of non-competitive conditions on farm-gate prices. We use total household area ${ }^{11}$ and livestock as proxies for wealth. We expect a less negative (or a positive) impact for wealthier households, households with large household area or larger livestock herds.

Finally, there is a considerable difference in literacy and educational attainment between farmers and non-farmers ${ }^{12}$. Around $45 \%$ of heads of farm households are literate compared to around $75 \%$ for non-farm households (Appendix, Table A15, middle panel). In other words, more than $50 \%$ of farm household heads cannot read or write: this will seriously hamper effective use of information obtained from mobile phones. The distribution of educational attainment is also more skewed towards no education in the case of farm households (close to 50\%), than in the case of non-farm households (around 20\%). Between $23 \%$ and $34 \%$ of non-farm households have $6-12$ years of education, while this share is around $10 \%$ for farmers (Appendix, Table A15, upper panel). Illiteracy and low levels of education

\footnotetext{
${ }^{10}$ Burke et al. (2018) show how solving credit constraints helps farmers benefit from seasonal price variation.

11 Total household area is agricultural land cultivated with permanent and annual crops plus fallow land. Total household area observations are not available for all survey years, notably 2006 (entirely missing) and 2008 (only a limited number of observations).

${ }^{12}$ We define farm households as households that report that agriculture is their main activity.
} 
are likely to adversely affect eagerness to exploit new technologies and proficiency in the use of mobile phones. A similar reasoning applies to age: heads of farm household are, on average, around 2 to 4 years older than their non-farm counterparts (Appendix, Table A15, lower panel). In summary, differences in literacy, educational attainment and age suggest that less benefits from mobile phones could be the result of less ability and eagerness on the side of farmers to purchase and use mobile phones and obtain improved market and price information. We use educational attainment of the household head as a proxy for communications skills, and ease and proficiency in employing new technologies ${ }^{13}$. We expect a less negative impact for higher levels of educational attainment: higher levels of education will help households quickly learn and adopt new communication technologies, develop skills and become proficient in using mobile phones and exploit their opportunities.

\section{Data, Sources, Availability and Variable Construction}

The data on the rollout of mobile phone infrastructure, sourced from the Ministry of Transport and Communication of Mozambique ${ }^{14}$, contain 547 mobile phone towers, their latitude and longitude coordinates and their first year of operation. The rollout data that we use stretch from 1997 to $2009^{15}$. We employ a range of $35 \mathrm{~km}$ around the mobile phone tower, as the crow flies, to identify markets and households that fall within the coverage area of a mobile phone tower ${ }^{16}$. Maize prices are from the weekly publication Quente-Quente, published by Sistema de

\footnotetext{
${ }^{13}$ The educational attainment information available in the TIA surveys distinguishes 'without formal education', grade 1 to 12 , 'college' and 'knows how to read and write'. Note that the group 'without formal education' is by far the largest single class, comprising $38 \%-45 \%$ of all households in each year. We have converted the educational attainment variable to a three class categorical variable distinguishing (1) 'without formal education', (2) grade 1-6 including 'knows how to read and write' and (3) grade 7 and higher, also including college.

${ }^{14}$ Mobile phone roll-out data were kindly made available by Jenny Aker.

${ }^{15}$ It is unlikely that further extension of the mobile phone network stopped in 2009. However, with the limited number of towns and cities identified in the market price data, the roll-out is completed in 2006 (Table A2). The household survey data have households without mobile phone coverage until 2008, the last survey year (Table A5).

${ }^{16}$ The range of a mobile phone tower (or Base Transceiver Station) is limited to $35 \mathrm{~km}$, but could vary with the height of antenna over surrounding terrain, the signal frequency and various other parameters.
} 
Informação de Mercados Agrícolas de Moçambique (SIMA; www.masa.gov.mz/sima). We use the weekly producer prices and market prices (respectively Quadro 2: Preço e Mudança Percentual a Nível Produtor (Mts/Kg) and Quadro 3, Preço e Mudança Percentual a Nível de Mercado Retalhista (Mts/kg)) of white maize grain (grão de milho branco). Each Monday, both producer and market prices are collected by interviewing three randomly selected traders in each market and for each commodity ${ }^{17}$. Producer prices are calculated as the average price that farmers receive for selling a given crop. Producer prices are recorded for 15 markets, while market prices are recorded for a larger set of 27 markets $^{18}$. The set of markets for which producer prices are recorded are, by construction, representative of Mozambique maize grain supply. Producer prices are not equivalent to farm-gate prices, since we do not know if transactions are made at the farm-gate. The reported producer prices reflect the average price itinerant traders have paid to farmers either at the farmgate, in the area surrounding the market, or in the market ${ }^{19}$. We restrict our estimations to location-date combinations that have observations for both producer prices and market prices, and use data for the period from July 1997 to December 2009. This period covers the actual period of the roll-out of mobile phone infrastructure in producer markets, three years before the start and three years after the completion of the rollout (Table A2).

Unfortunately, there are missing observations in the price data (Appendix, Table A1 for availability of price data by market). At first glance, the reported numbers of missing observations are concerning: only Chimoio and Manica have reasonably complete data.

\footnotetext{
${ }^{17}$ Hence the SIMA price data, published every Wednesday, are actually daily quotations, recorded once a week on Mondays, rather than weeklies, i.e. weekly averages of quotations recorded seven days a week.

${ }^{18}$ Alto Molocue, Angoche, Angonia, Beira, Chimoio, Chokwe, Cuamba, Gorongosa, Lichinga, Manica, Maputo, Massinga, Maxixe, Milange, Mocuba, Monapo, Montepuez, Mutarara, Nacala, Nampula, Nhamatanda, Pemba, Quelimane, Ribaue, Tete, Vilanculos en Xai-Xai. Markets for which producer prices are recorded are in italics (Appendix, Figure A1 is a map with the locations of these markets).

${ }^{19}$ Likewise, the transactions underlying the unit values of household maize sales also have taken place either at the farmgate, on the market or somewhere in between (Appendix, Table A8). A comparison, by year and province, of producer prices and unit values of household maize sales indicates that both series are not wide apart (Appendix, Figure A10).
} 
However, missing data are quite common in agricultural markets. During large parts of the season there are simply no transactions taking place because of lack of supply. SIMA staff confirms that missing data are the result of no transactions in the market ${ }^{20}$. Most farm households sell maize directly after harvest, during a short time span, not longer than three to five months. More than $80 \%$ of all maize grain transactions take place during five consecutive months, from June to October (Appendix, Figure A9). Other research confirms farmers' sales during a limited number of months following harvest, mostly when prices are lowest (Courtois and Subervie, 2015; Burke et al., 2019). Hence 5 to 6 months of missing observations is normal, while substantially fewer missing observations is extraordinary. For a few markets occasional and non-systematic crop failures and the associated lack of supply, further reduce the number of price observations. Overall, this evidence suggests that the prevalence of missing observations is driven by standard seasonality and adverse weather conditions in specific areas. A regression of missing observations on mobile phone coverage and the estimation of treatment effect bounds (Lee bounds; see Appendix, Table A3 and A4) formally support that missing observations are not correlated with mobile phone coverage, and that estimated impacts broadly move within the treatment effect bounds. We therefore conclude that sample selection due to missing observations is not a major concern.

Jointly with the market price data we exploit household survey data to run the same impact estimations as in the case of on market price data, to investigate heterogeneity in impacts and to illustrate stylized facts about farmers. The national Mozambique household surveys, the so-called Trabalho de Inquérito Agrícola (TIA, renamed to Inquérito Agrícola Integrado (IAI) from 2012 onwards) - collected by the Mozambique Ministry of Agriculture - are nationally

\footnotetext{
${ }^{20}$ The weekly SIMA price bulletins are available for all weeks. Also, the SIMA bulletins record prices for other crops in the market-week in which maize prices are missing. Both facts support the idea that the price survey was run every week but that maize was simply unavailable in the market.
} 
representative agricultural surveys of small and medium sized farm owners ${ }^{21}$. With the exception of two survey years, the TIAs are representative cross-sectional surveys rather than a panel of households surveys. We use the available survey years that overlap with the rollout period of the mobile phone infrastructure $(2002,2003,2005,2006,2008)$. Summary statistics shown in Table 1 highlight the difference between farm and non-farm households, where the latter also contains local traders: farm households typically have older household heads, are more biased towards female gender, are less educated and less literate, less wealthy in terms of area and livestock, live in more remote areas, and sell maize at lower prices.

Table 1 Summary statistics of household surveys

\begin{tabular}{lcc}
\hline \hline & $\begin{array}{c}\text { Farm } \\
\text { Households } \\
\text { mean (sd) }\end{array}$ & $\begin{array}{c}\text { Non-farm } \\
\text { households } \\
\text { mean (sd) }\end{array}$ \\
\hline Age of the household head (years) & $45.2(15.2)$ & $42.5(14.1)$ \\
Gender of the household head (male=0; female=1) & $0.270(0.444)$ & $0.095(0.293)$ \\
Educational attainment (no education = 0; any =1) & $0.536(0.499)$ & $0.755(0.430)$ \\
Literacy (yes = 1; no= 0) & $0.438(0.496)$ & $0.750(0.433)$ \\
Household size (number of members) & $5.718(3.417)$ & $6.536(3.720)$ \\
Household area (ha) & $2.146(3.945)$ & $2.403(11.061)$ \\
Livestock (tropical livestock units)* & $2.057(4.659)$ & $2.827(5.814)$ \\
Livestock (share of households with non-zero livestock, \%) & $76.1(3.734)$ & $73.9(7.575)$ \\
Maize grown (yes = 1; no = 0) & $0.800(0.400)$ & $0.817(0.387)$ \\
Selling maize (yes = 1; no = 0) & $0.180(0.384)$ & $0.074(0.261)$ \\
Sales unit value (conditional; constant 2010 prices) & $5.697(6.065)$ & $6.224(5.298)$ \\
Distance to tarred road (km, only 2005) & $54.2(71.7)$ & $36.7(59.3)$ \\
\hline \hline
\end{tabular}

Source: Trabalho de Inquérito Agrícola (2002, 2003, 2005, 2006, 2008)

Note: Farm households are households that indicate that agriculture is their main activity. Livestock is converted to tropical livestock units using weights from FAO, 2011, Guidelines for the preparation of livestock sector reviews. Animal Production and Health Guidelines. No. 5. Rome. * conditional on non-zero livestock.

We use a few other variables in our market-based empirical work, primarily for estimations with covariates. Population data, both by district and by city or town, are from three censuses $(1997,2007,2016)$ from the Instituto Nacional de Estatistica Moçambique and constructed by interpolation for intermediate months and years. Population is used to calculate population and network density. Population density is defined as population by area and calculated as district

\footnotetext{
${ }^{21}$ Small sized farms are less than 1 ha $(<1)$; medium sized farms are between 1 and 2 ha $(\geq 1$ and $<2)$.
} 
population per $\mathrm{km}^{2}$. Our network density variable is calculated as the sum of the population of towns divided by road distance to these towns, network density $y_{i}=\sum_{j}$ (population $_{j}$ ) road distance $e_{i j}$ ) where $i$ and $j$ are towns and $i \neq j^{22}$. Network density reflects the degree to which markets are embedded in a population weighted network of cities and towns. We have obtained distance, both road distance and Euclidian distance ("as the crow flies"), in kilometers from GoogleMaps, accessed at the start this study (2017). The variable distance to large cities is the shortest road distance from a specific market to either Maputo, Beira or Nampula. Finally, we use national monthly consumer prices for Mozambique, which are taken from the IMF International Financial Statistics. Consumer prices are used to deflate nominal series.

\section{Estimation Results, Parallel Trends, Robustness and Heterogeneity}

\section{Estimating a basic specification}

We start with estimating equation (6) using OLS with standard errors clustered by market, the level of the intervention assignment. Estimation results, reported in Table 2, indicate that the margin has increased by between $11.6 \%$ and $12.6 \%$ due to the introduction of mobile phones, where both impact coefficients are significant at the 5\% level. This increase is combined with a statistically significant decrease of real producer prices by between $12.2 \%$ and $13.2 \%$, and an insignificant and negligible change in real market prices. Since the increase in margin is captured by traders, we conclude that the benefits from introducing mobile phones are positive for traders and negative for farmers.

\footnotetext{
${ }^{22}$ The inverse distance weights are standard in panel estimations that control for spatial spillovers (the STATA command spxtreg).
} 
Table 2 Impact of mobile phones on prices and margins: full sample, DiD-OLS

\begin{tabular}{|c|c|c|c|c|c|c|}
\hline dependent variable & \multicolumn{2}{|c|}{$\begin{array}{l}\ln (\operatorname{margin}) \\
\ln \left(\mathrm{p}_{\mathrm{m}} / \mathrm{p}_{\mathrm{f}}\right)\end{array}$} & \multicolumn{2}{|c|}{$\begin{array}{c}\ln (\text { producer price }) \\
\ln \left(\mathrm{p}_{\mathrm{f}}\right)\end{array}$} & \multicolumn{2}{|c|}{$\begin{array}{c}\ln (\text { market price }) \\
\ln \left(\mathrm{p}_{\mathrm{m}}\right)\end{array}$} \\
\hline mobile phone & $\begin{array}{l}0.116^{* *} \\
(0.049)\end{array}$ & $\begin{array}{l}0.126^{* *} \\
(0.048)\end{array}$ & $\begin{array}{l}-0.132^{* *} \\
(0.059)\end{array}$ & $\begin{array}{c}-0.122^{* *} \\
(0.053)\end{array}$ & $\begin{array}{l}-0.016 \\
(0.089)\end{array}$ & $\begin{array}{c}0.004 \\
(0.083)\end{array}$ \\
\hline Covariates & No & Yes & no & Yes & No & Yes \\
\hline $\mathrm{R}^{2}$ & 0.495 & 0.501 & 0.847 & 0.848 & 0.854 & 0.857 \\
\hline no. of observations & 3021 & 3021 & 3021 & 3021 & 3021 & 3021 \\
\hline
\end{tabular}

Note: Maize price data are from July 1997 to December 2009 (source: SIMA). Estimations include market and year-month fixed effects, and control for market specific seasonality. Prices are deflated with the national consumer price index. Covariates are population size, elevation and distance to big cities, all in natural logarithms. Standard errors clustered by market are in parentheses below the coefficients. ${ }^{*} p<0.10,{ }^{* *} p<0.05,{ }^{* * *} p<0.01$.

The impact estimates support increased imbalances in bargaining power between farmers and traders and (or) non-competitive pricing of traders, in contrast with claims of others (Sitko and Jayne, 2014; Dillon and Dambro, 2017). We proceed with estimating the impact of mobile phones on household unit values of maize sales, specified in equation (7), using household survey data and explore if the results based on market data are consistent with results based on household survey data. The data on the rollout of the mobile phone infrastructure (mobile phone towers) are matched with the location of households. Households have mobile phone coverage if an operational mobile phone tower is less than $35 \mathrm{~km}$ (as the crow flies) away from the location of the household. Unfortunately not all households have location coordinates. We have increased the number of observations for estimation by enlarging the coverage area of coordinates and mobile phones (Empirical strategy and Appendix, Table A5).

Table 3 Impact of mobile phones on household selling prices

\begin{tabular}{lcc|cc|cc}
\hline dependent variable: $\ln ($ selling price) & $(1)$ & $(2)$ & $(3)$ & $(4)$ & $(5)$ & $(6)$ \\
\hline mobile phone & $-0.229^{* * *}$ & $-0.234^{* * *}$ & $-0.184^{* *}$ & $-0.188^{* *}$ & $-0.132^{* *}$ & $-0.132^{* *}$ \\
& $(0.076)$ & $(0.075)$ & $(0.071)$ & $(0.072)$ & $(0.056)$ & $(0.056)$ \\
year x province (binary) & Yes & Yes & yes & Yes & yes & Yes \\
primary sampling unit (binary) & Yes & Yes & yes & Yes & yes & Yes \\
Covariates & No & Yes & no & Yes & no & Yes \\
$\mathrm{R}^{2}$ & 0.462 & 0.463 & 0.414 & 0.415 & 0.364 & 0.364 \\
no. of observations & 1947 & 1947 & 2425 & 2425 & 3828 & 3826 \\
\hline \hline
\end{tabular}

Note: Selling prices are unit values of maize grain sales taken from the household survey Trabalho de Inquérito Agrícola (2002, 2003, 2005, 2006 and 2008). Columns (1) and (2) are restricted to households with location coordinates. Columns (3) and (4) uses primary sampling units to extend the mobile phone coverage data, and columns (5) and (6) further extends this by exploiting district information. Covariates are gender, age and education of the household head, and household size (number of family members). Age and household size are in natural logarithms. Standard errors clustered by district are reported in parentheses below the coefficient. ${ }^{*} p<0.10,{ }^{* *} p<0.05,{ }^{* * *} p<0.01$. 
The estimation results, reported in Table 3, all indicate a negative impact of 'falling within the coverage area of a mobile phone tower' on realized maize selling prices: the household survey data show a decrease in household selling prices of $11 \%$ to $20 \%$, at the $5 \%$ level of accuracy in all but one estimation. The negative impact of mobile phones on selling prices for farm households is consistent with an increase in margins and a decrease in producer prices - the outcome of estimations based on market data.

\section{Parallel trend test}

In the DiD estimation trends in outcomes in the pre-introduction period need to be the same for both intervention and control observations. We investigate graphically if margins and prices follow parallel trends before the introduction of mobile phones. The graphical evidence visualizes the entire dynamic path of impact, and thereby also reveals whether impacts are stable and persistent, and decreasing or increasing over time. We estimate a variant of equation (1) in order to find the required information: the impact variable is replaced with a set of annual indicator variables reflecting the number of years before and after the introduction of mobile phones $^{23}$. If markets with and without mobile phones are on the same trend in the preintroduction period, then the pre-introduction coefficients should be insignificant. In that case the difference in differences is not significantly different from zero between the two groups during this period (Autor, 2003).

\footnotetext{
${ }^{23}$ Hence, if $D(y e a r=0)$ is an indicator variable with a value of 1 in the year of introduction and zero elsewhere, then $D($ year $=-1)$ is an indicator variable with a value of 1 one year before introduction and zero elsewhere, etc. Note that the year of introduction of mobile phones differs by market.
} 
Figure 1a Testing for a parallel trend: impact of mobile phones on margins

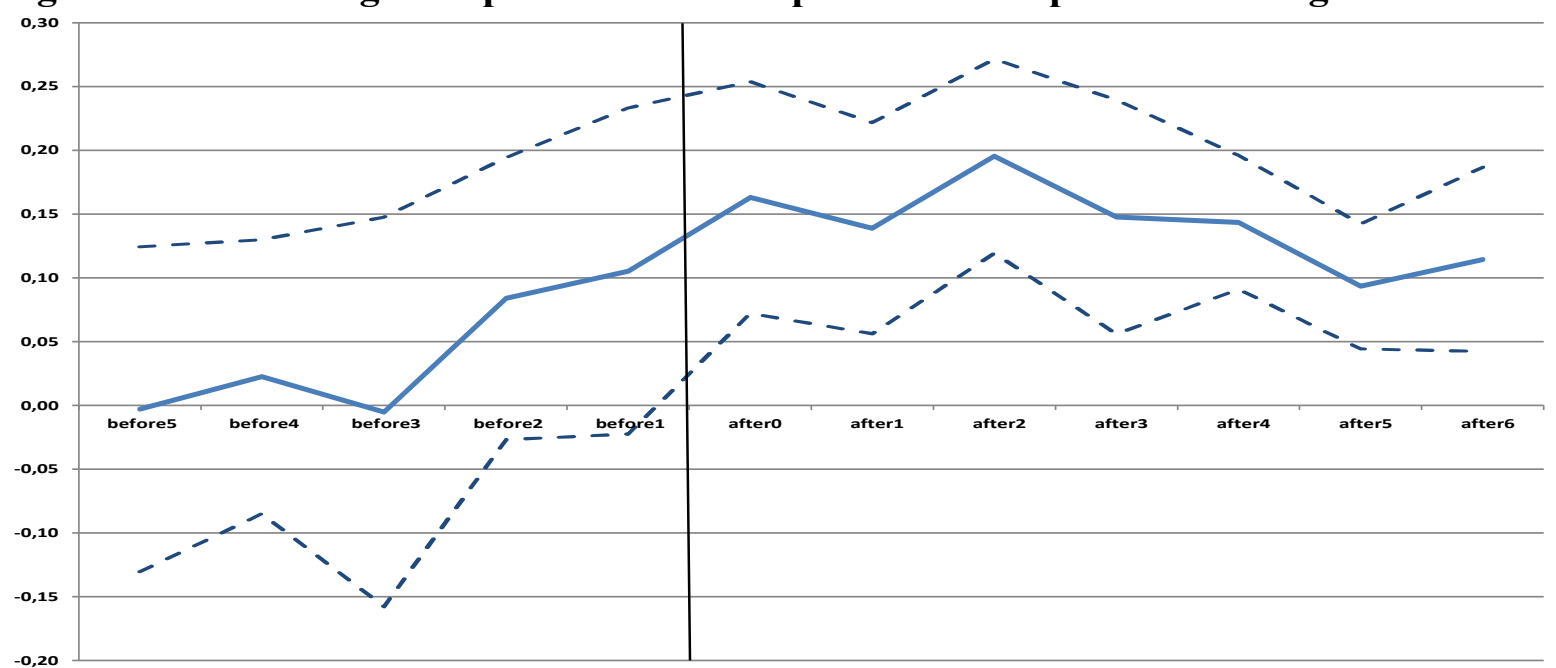

Figure 1b Testing for a parallel trend: impact of mobile phones on producer prices

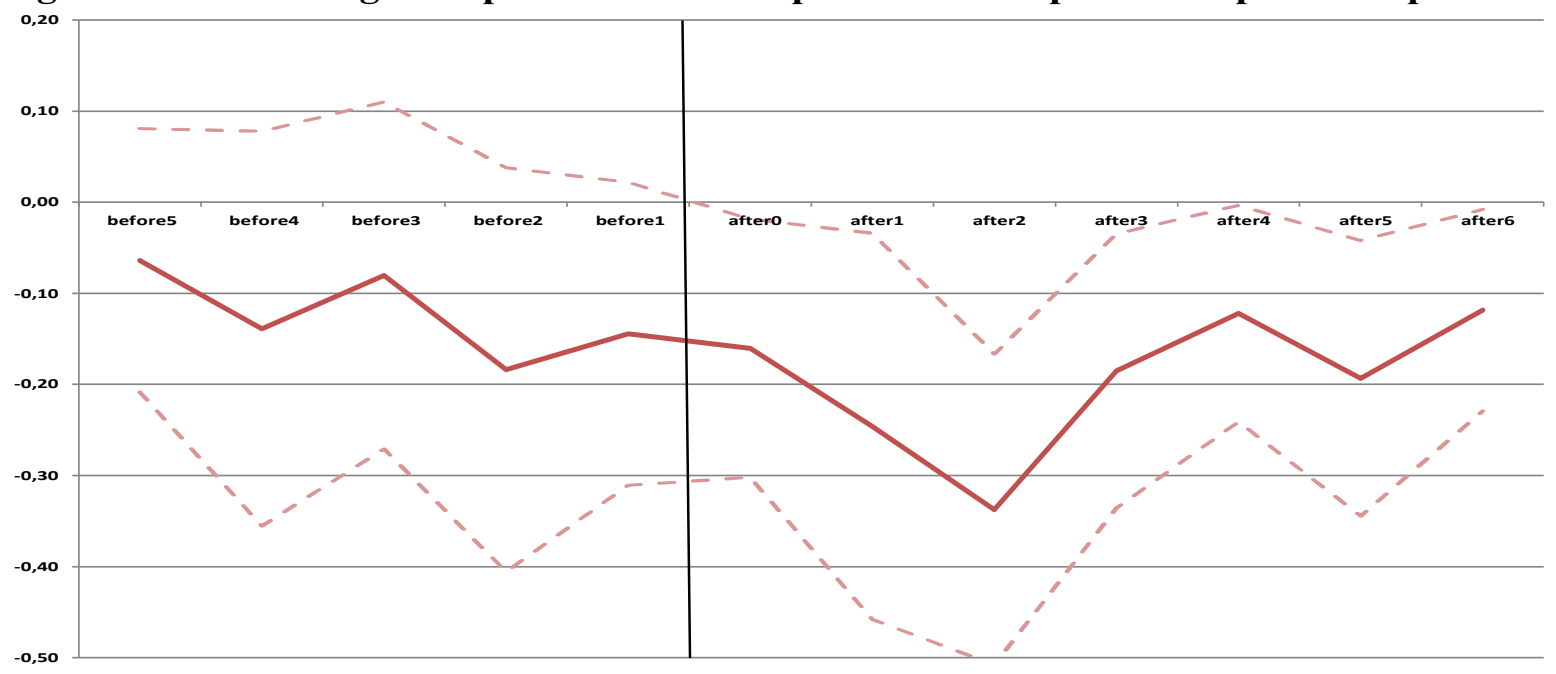

Figure 1c Testing for a parallel trend: impact of mobile phones on market prices

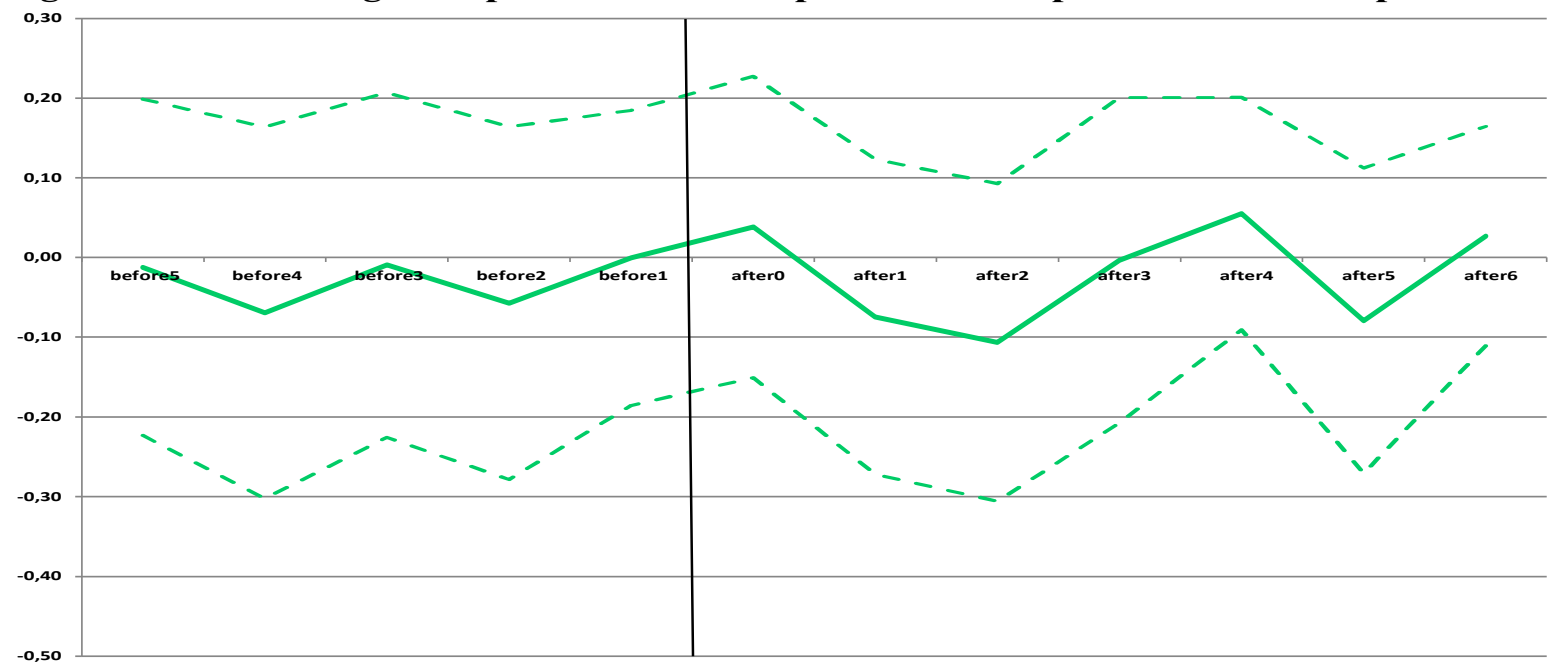

Note: dotted lines indicate $95 \%$ confidence intervals 
The results of this exercise for margins, shown in Figure 1a, illustrate that before coefficients are statistically insignificant and thereby support a parallel trend in the observations before the introduction of mobile phones. The figure further indicates statistically significant positive impacts on margins after the introduction of mobile phones, that appear to level off after a few years. This could indicate a delay in the take-up of mobile phones by farmers versus traders. Traders, as a group, interact more intensively and are likely to be faster in purchasing mobile phones and in exploiting the opportunities of this new information technology compared to farmers living far away from cities and towns. A decrease in impact over the years is formally confirmed by the evidence: a test rejects equality between the maximum impact after introduction and impact in the $5^{\text {th }}$ or $6^{\text {th }}$ year after introduction.

We have repeated the parallel trend tests for producer prices and market prices: as in the case of margins we observe statistically insignificant coefficients before introduction, supporting parallel trends in the observations before the introduction of mobile phones ${ }^{24}$. For producer prices this is combined with similarly sized and statistically significant negative after introduction coefficients (Figure 1b). Producer prices decrease after the introduction of mobile phones and, the development over time mirrors the development of impacts on margins: after a few years the decrease of producer prices becomes smaller, suggesting that farmers catch up in the take-up of mobile phones. For market prices parallel trends before the introduction are also confirmed, but we find no significant after introduction coefficients (Figure 1c). The consistently insignificant coefficients support the claim that market prices in producer areas are not affected by the introduction of mobile phones. Overall, outcomes reported in the figures make us confident about both margin and producer price estimation results reported in Table 1.

\footnotetext{
${ }^{24}$ In both figures we observe that statistical significance improves in the years before introduction of mobile phones. We attribute this to spill-over effects between markets which are discussed in the remainder of this section.
} 
Figure 2 Testing for a parallel trend: impact of mobile phones on household selling prices

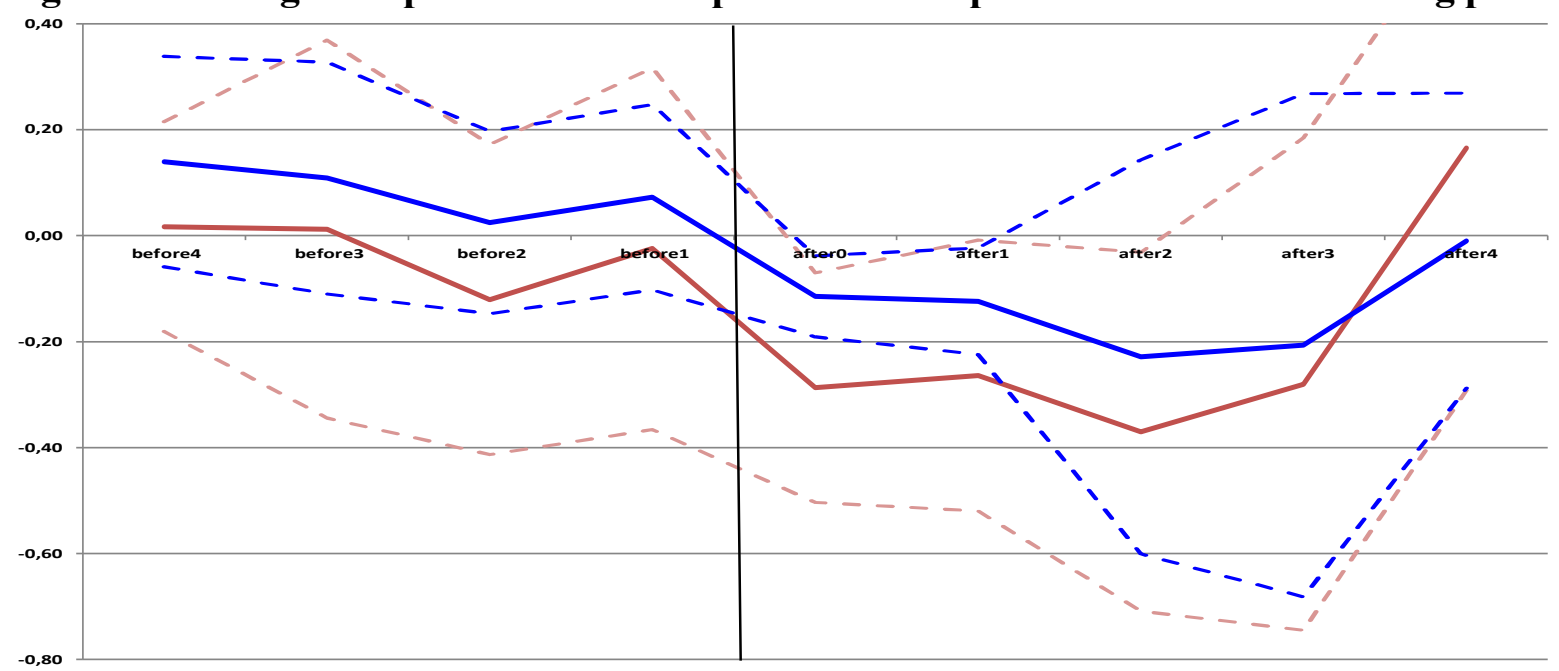

Note: dotted lines indicate $95 \%$ confidence intervals. The red lines are calculated on the basis of sample A, the blue lines on the basis of sample B.

A parallel trend test on the basis of household survey data (Figure 2) confirms parallel trends in the pre-intervention period and significant negative impacts in the post intervention period. The pattern of impact on household selling prices corresponds closely with the pattern of impacts on producer prices (Figure 1b). Note, however, that the reduction in impact beyond three years after introduction becomes less accurate due to few observations.

\section{Robustness checks}

A small recent literature has indicated the risk of biases in TWFE DiD impact estimations in the case of staggered intervention designs (Goodman-Bacon, 2018; de Chaisemartin and d'Haultfœulle, 2020; Jakiela, 2021). We implement the suggested diagnostic tests and robustness checks to investigate the severity of potential biases in our market data based estimations. All tests and robustness checks require balanced data: unfortunately our original weekly price and margin data are highly unbalanced. Following Aker (2010), we balance the price data by collapsing into annuals and re-run estimations and parallel trend tests: the results based on this admittedly much smaller but strongly balanced data set confirm Table 2 and 3 estimations, and parallel trend tests (Appendix Table A15; Figure A11). We proceed with 
implementing the diagnostic tests and robustness checks (Goodman-Bacon, 2018; de Chaisemartin and d'Haultfœulle, 2020; Jakiela, 2021). Biases in impact coefficients are caused by negative weights of intervention observations and by heterogeneity in impact. We find weights by regressing the mobile phone coverage on market and year fixed effects and split the residuals into intervention and comparison group. The distribution of weights (Appendix, Figure 12 ) shows $21 \%$ and $22 \%$ negative weights. Negative weights are without exception later year observations from early adopters ${ }^{25}$, similar to what is found elsewhere (Jakiela, 2021). As robustness checks we re-run the impact estimations by retaining a maximum number of post treatment years, and report size and confidence intervals of the impact coefficient with increasing number of omitted observations (Appendix, Figure A13). We find that the size and accurateness decrease when more observations are omitted, but impacts remain on the whole reasonably stable. We conclude that the negatively weighted intervention observations are not driving the result. Next, we investigate homogeneity of impact by exploiting the fact that the relationship between the residualized outcome variable and the residualized treatment variable is linear, under the assumption of homogeneity in impact and common trends, and that the slope is the same for intervention and comparison group (Jakiela, 2021). On the basis of our test regression we cannot reject equality of this slope, both for margins and producer prices (Appendix, Table A13), although the evidence is not strong. We conclude that the homogeneity assumption is weakly supported by our data.

The identifying assumption in the DiD estimation requires that there are no spillovers between treated and non-treated units. With local traders travelling around, sharing information within their network, both temporal and spatial spillovers are intuitively likely. Spillovers are also partly visible in the empirical estimations: we find margins increasing and producer price

\footnotetext{
${ }^{25}$ Notably the later years observations of the markets Chokwe (2000), Chimoio (2000), Manica (2000) and Nhamatanda (2002), with the year of introduction in parentheses.
} 
decreasing prior to cell tower arrival (Figure 1). With the presented estimations we are, in fact, in the position to assess the degree of spatial and temporal spillovers. In estimations based on household survey data, we use three different ways to identify households with mobile phone coverage, reflecting an increasingly larger coverage area (Table 3). These estimations are thereby a test of the degree of spatial spillovers. In case of spatial spillovers we expect increases in impact with larger coverage area. Inspecting the estimations (Table3), we see that impacts on household selling prices decrease with (constructed) mobile phone coverage that is spatially larger. We conclude that the extent of spatial spillovers is negligible. The tests of temporal spillovers are addressed in the analysis of the staggered intervention design of the market data based estimations. The estimations with the balanced annual data reveal the degree of temporal spillovers (Table A15; Figure A11). The larger impact with annualized data point to temporal spillovers and suggests that estimations with weekly data reflect lower bounds to impact.

The choice of the sample period in the estimations is to some degree arbitrary. Mobile phone technology - in our sample of markets - is introduced in 2000 and fully rolled-out in 2006. Extending the sample period prior to 2000 and beyond 2006 is not necessary, and may adversely affect the accuracy of impact estimates through potential confounding factors. Moreover, estimations with variation in treatment timing are claimed to be sensitive to the chosen sample period (Goodman-Bacon, 2018). Hence, we have re-run the basic specification with a variety of starting years (1997-2000) and ending years (2006-2009), a total of 16 different sample periods. Estimations with varying starting and ending year generate reasonable stable impact coefficients (Table A16). There are no sign reversals in margin and producer price impacts (Goodman-Bacon, 2018). Significance improves with later starting and ending years, with the best results in terms of significance of margin and producer price impacts for the sample period 2000-2009. Estimation results indicate margin increases varying from $9 \%$ to $22 \%$, and producer price decreases varying from $14 \%$ to $21 \%$, significant at the $1 \%$ level. 
Next, it appears sensible to concentrate the observations used in estimations to the trading season. The price data show strong seasonality with a large common component, but also varying in timing and amplitude between markets and years. Due to lack of supply there are missing observations in the lean season (Appendix, Figure A8 for data availability by month). In other words: during the lean season markets are thin and likely to show large and erratic price fluctuations. These periods are less informative about regular market responses. In the basic specification we have controlled for seasonality by including market specific monthly dummies (along with market fixed effects). Another approach is to restrict estimations to months outside the lean season, months with sufficient data availability. Although lean season months vary across markets, the last and first two months of the calendar year, from November to February, rarely have many observations. Hence, we have re-estimated equations restricting the sample to the remaining months. Restricting the sample to observations from March to October - months after harvest, with potentially large trade volumes - improves significance and increases the size of the impact, with margin increases varying from $17 \%$ to $22 \%$, and producer price decreases between $17 \%$ and $21 \%$ (Table A17).

Finally, we employ a geographical division in the estimations. Mozambique is a large country: road distance from north to south (Pemba-Maputo) is 2500-2800km (for comparison: New York-Houston (Texas): 2650km; Amsterdam-Gibraltar: 2400-2600km). Differences in impact are possibly associated with differences in behavior and circumstances in different parts of the country. A natural way to divide the country is by considering markets north and south of the Zambezi river. Markets on either side of the Zambezi are likely to operate somewhat independently, due to high transport costs of trade across the Zambezi river (Zant, 2021). Major flows of maize grain are, north of the Zambezi, from west to east, and, south of the Zambezi, from central to south: producer areas in the north (like Mocuba and Cuamba) supply cities and towns on the coastline, north of the Zambezi (like Nampula and Nacala), while producer areas 
in the central region (like Manica and Chimoio) supply regions in the south and Maputo (Zant, 2021). Hence, we estimate impacts on both sides of the Zambezi separately. Estimations for north and south of the Zambezi show more modest but still significant margin increases, combined with large producer prices decreases and, in the north, market price decreases (Table A18 to A19). We also implemented the north-south split in the estimations with household data (Table A21 and A22). The estimated impacts are clearly less accurate but still convincingly support the main results.

\section{Heterogeneity of impacts}

Next, we investigate heterogeneity in impacts on margins by estimating if impacts are correlated with competitiveness and with terminal market prices, and we investigate heterogeneity in impacts on household selling prices by estimating if impacts are correlated with wealth and educational attainment of farmers. Estimation results on heterogeneity of impacts on margins by degree of competitiveness - where competitiveness is approximated by network density and population density - are presented in Table 4a.

Markets with a low population or network density show a positive, statistically significant and large impact of mobile phones on traders' margins. However, a high network or population density exerts a statistically significant negative impact on traders' margins. This negative impact causes a major reduction in the positive impact of mobile phones on traders' margins, and (in one case) completely offsets this positive impact. These results suggest that the introduction of mobile phones becomes beneficial to farmers rather than to traders if network density is high and markets are presumably more competitive. Conversely, remote and isolated markets, with a low population density, and poorly embedded in a network of cities and towns show margin increases due to mobile phones. This outcome indicates that the margin increases due to mobile phones are associated with remote areas, where traders operate under less competitive conditions. Muto and Yamano (2009) also report increased market participation 
of farmers in remote areas after the introduction of mobile phones in Uganda. Results are robust to different ways of converting the network or population density variable into an indicator variable. We investigate if traders have expanded their geographical domain to realize lower purchase prices. We find that the average distance of households with mobile phone coverage (and maize sales) to the nearest market has increased till 2006 and afterwards drops sharply (Figure A14). We conjecture that the drop can be attributed to the 2007 flooding. Hence, this evidence supports expansion of traders activities into remote areas due to mobile phones.

Table 4a Are margin impacts correlated with network and population density?

\begin{tabular}{l|cc|cc}
\hline \hline dependent variable: $\ln ($ margin) & \multicolumn{1}{|c|}{$(1)$} & $(2)$ & $(3)$ & $(4)$ \\
& \multicolumn{2}{|c|}{ network density } & \multicolumn{2}{c}{ district population density } \\
\hline mobile phone & $0.126^{* * *}$ & $0.127^{* * *}$ & $0.175^{* * *}$ & $0.135^{*}$ \\
& $(0.042)$ & $(0.029)$ & $(0.029)$ & $(0.066)$ \\
mobile phone * above median & $-0.099^{* * *}$ & $-0.142^{* * *}$ & $-0.111^{* * *}$ & $-0.093^{*}$ \\
& $(0.032)$ & $(0.036)$ & $(0.028)$ & $(0.045)$ \\
Covariates & No & yes & no & yes \\
$\mathrm{R}^{2}$ & 0.546 & 0.554 & 0.552 & 0.553 \\
no. of observations & 2558 & 2558 & 2558 & 2558 \\
\hline \hline
\end{tabular}

Table 4b Are margin impacts correlated with terminal market prices?

\begin{tabular}{|c|c|c|c|c|}
\hline dependent variable: $\ln ($ margin $)$ & \multicolumn{2}{|c|}{$\begin{array}{l}\text { terminal market price: } \\
\text { Maputo }\end{array}$} & \multicolumn{2}{|c|}{$\begin{array}{c}\text { terminal market price: } \\
\text { Nampula }\end{array}$} \\
\hline mobile phone & $\begin{array}{c}0.038 \\
(0.039)\end{array}$ & $\begin{array}{l}-0.043 \\
(0.053)\end{array}$ & $\begin{array}{l}0.094^{*} \\
(0.049)\end{array}$ & $\begin{array}{l}-0.001 \\
(0.055)\end{array}$ \\
\hline mobile phone $*$ tercile 2 & $\begin{array}{l}0.064^{* *} \\
(0.022)\end{array}$ & $\begin{array}{l}0.072^{* * *} \\
(0.019)\end{array}$ & $\begin{array}{l}0.023^{*} \\
(0.013)\end{array}$ & $\begin{array}{l}0.026^{* *} \\
(0.010)\end{array}$ \\
\hline mobile phone $*$ tercile 3 & $\begin{array}{l}0.160^{* * *} \\
(0.023)\end{array}$ & $\begin{array}{l}0.167^{* * *} \\
(0.021)\end{array}$ & $\begin{array}{l}0.106^{* * *} \\
(0.018)\end{array}$ & $\begin{array}{l}0.116^{* * *} \\
(0.016)\end{array}$ \\
\hline Covariates & No & yes & no & yes \\
\hline $\mathrm{R}^{2}$ & 0.581 & 0.597 & 0.565 & 0.584 \\
\hline no. of observations & 2558 & 2558 & 2558 & 2558 \\
\hline
\end{tabular}

Note: Maize price data are from July 1997 to December 2009 (source: SIMA). Estimations include market and year-month fixed effects, and control for market specific seasonality. Covariates are population size, network density, district population density, elevation and distance to big cities, all in natural logarithms. Network density is the sum of market population weighted by the inverse of road distance (network density $_{i}=$ $\sum_{j}$ (population $_{j} /$ road distance $e_{i j}$ ) where $i$ and $j$ are markets and $i \neq j$ ). District population density is district population divided by district area. The difference with terminal market prices is the market price in large cities over the local producer price $\left(\mathrm{p}_{\mathrm{m}}\right.$, bigcity $\left./ \mathrm{p}_{\mathrm{f}}\right)$. Standard errors clustered by market are in parentheses below the coefficients. ${ }^{*} p<0.10,{ }^{* *} p<0.05,{ }^{* * *} p<0.01$.

Our estimation results on heterogeneity of impacts on margins by terminal market prices, presented in Table 4b, consistently support statistically significant impacts for larger 
price differences. The impacts of mobile phones on traders' margins increase with the size of the price difference, and are mostly insignificant for relatively moderate or small price differences. Hence, a positive impact on traders' margins occurs particularly - and nearly exclusively - when the price difference with distant urban markets is large, and more so if this price difference is larger. Again, these results are robust to different ways of converting the price difference with terminal markets into an indicator variable.

Table 5a Are impacts on household selling prices correlated with household wealth?

\begin{tabular}{|c|c|c|c|c|c|c|}
\hline $\begin{array}{c}\text { dependent variable: } \\
\ln (\text { selling price })\end{array}$ & (1) & (2) & (3) & (4) & (5) & (6) \\
\hline & \multicolumn{6}{|c|}{ household area size } \\
\hline mobile phone & $\begin{array}{c}-0.235^{* * *} \\
(0.079)\end{array}$ & $\begin{array}{c}-0.238^{* * *} \\
(0.076)\end{array}$ & $\begin{array}{l}-0.179^{* *} \\
(0.068)\end{array}$ & $\begin{array}{l}-0.182^{* *} \\
(0.069)\end{array}$ & $\begin{array}{l}-0.130^{* *} \\
(0.060)\end{array}$ & $\begin{array}{l}-0.129^{* *} \\
(0.060)\end{array}$ \\
\hline mobile phone $*$ tercile 2 & $\begin{array}{c}0.063 \\
(0.112)\end{array}$ & $\begin{array}{c}0.060 \\
(0.109)\end{array}$ & $\begin{array}{l}-0.035 \\
(0.111)\end{array}$ & $\begin{array}{c}-0.038 \\
(0.110)\end{array}$ & $\begin{array}{l}-0.028 \\
(0.081)\end{array}$ & $\begin{array}{l}-0.029 \\
(0.080)\end{array}$ \\
\hline mobile phone $*$ tercile 3 & $\begin{array}{l}-0.044 \\
(0.087)\end{array}$ & $\begin{array}{l}-0.053 \\
(0.087)\end{array}$ & $\begin{array}{c}0.027 \\
(0.082)\end{array}$ & $\begin{array}{c}0.019 \\
(0.083)\end{array}$ & $\begin{array}{c}0.021 \\
(0.061)\end{array}$ & $\begin{array}{c}0.018 \\
(0.060)\end{array}$ \\
\hline year x province (binary) & yes & yes & Yes & yes & yes & Yes \\
\hline primary sampling unit (binary) ${ }^{*}$ & yes & yes & Yes & yes & yes & Yes \\
\hline Covariates & yo & yes & No & yes & no & Yes \\
\hline $\mathrm{R}^{2}$ & 0.462 & 0.463 & 0.414 & 0.415 & 0.364 & 0.364 \\
\hline \multirow[t]{2}{*}{ no. of observations } & 1947 & 1947 & 2425 & 2425 & 3828 & 3826 \\
\hline & \multicolumn{6}{|c|}{ livestock } \\
\hline mobile phone & $\begin{array}{c}-0.306^{* * *} \\
(0.087)\end{array}$ & $\begin{array}{c}-0.305^{* * *} \\
(0.087)\end{array}$ & $\begin{array}{c}-0.288^{* * *} \\
(0.082)\end{array}$ & $\begin{array}{c}-0.286^{* * *} \\
(0.082)\end{array}$ & $\begin{array}{c}-0.236^{* * *} \\
(0.053)\end{array}$ & $\begin{array}{c}-0.233^{* * *} \\
(0.051)\end{array}$ \\
\hline mobile phone $*$ tercile 2 & $\begin{array}{c}0.058 \\
(0.060\end{array}$ & $\begin{array}{c}0.053 \\
(0.056)\end{array}$ & $\begin{array}{c}0.111 \\
(0.070)\end{array}$ & $\begin{array}{c}0.106 \\
(0.071)\end{array}$ & $\begin{array}{l}0.117^{* *} \\
(0.056)\end{array}$ & $\begin{array}{c}0.117^{*} \\
(0.058)\end{array}$ \\
\hline mobile phone $*$ tercile 3 & $\begin{array}{l}0.236^{* * *} \\
(0.068)\end{array}$ & $\begin{array}{l}0.224^{* * *} \\
(0.073)\end{array}$ & $\begin{array}{l}0.249^{* * *} \\
(0.091)\end{array}$ & $\begin{array}{l}0.237^{* *} \\
(0.096)\end{array}$ & $\begin{array}{l}0.245^{* * *} \\
(0.062)\end{array}$ & $\begin{array}{l}0.242^{* * *} \\
(0.066)\end{array}$ \\
\hline year x province (binary) & yes & yes & Yes & yes & yes & Yes \\
\hline primary sampling unit (binary) ${ }^{*}$ & yes & yes & Yes & yes & yes & Yes \\
\hline Covariates & no & yes & No & yes & no & Yes \\
\hline $\mathrm{R}^{2}$ & 0.465 & 0.465 & 0.418 & 0.418 & 0.368 & 0.368 \\
\hline no. of observations & 1947 & 1947 & 2425 & 2425 & 3828 & 3826 \\
\hline
\end{tabular}


Table 5b Are impacts on household selling prices correlated with educational attainment?

\begin{tabular}{l|cc|cc|ccc}
\hline $\begin{array}{c}\text { dependent variable: } \\
\ln (\text { selling price) }\end{array}$ & $(1)$ & $(2)$ & $(3)$ & $(4)$ & $(5)$ & $(6)$ \\
\hline & \multicolumn{7}{|c|}{ educational attainment of the household head } \\
\hline mobile phone & -0.191 & -0.188 & -0.162 & -0.163 & -0.130 & -0.134 \\
& $(0.128)$ & $(0.135)$ & $(0.106)$ & $(0.114)$ & $(0.079)$ & $(0.082)$ \\
mobile phone * any formal education & -0.062 & -0.075 & -0.036 & -0.041 & -0.003 & 0.004 \\
& $(0.112)$ & $(0.131)$ & $(0.097)$ & $(0.111)$ & $(0.055)$ & $(0.058)$ \\
year x province (binary) & yes & Yes & yes & yes & yes & yes \\
primary sampling unit (binary) & yes & Yes & yes & yes & yes & yes \\
Covariates & no & Yes & no & yes & no & yes \\
$\mathrm{R}^{2}$ & 0.462 & 0.463 & 0.414 & 0.414 & 0.364 & 0.364 \\
no. of observations & 1947 & 1947 & 2425 & 2425 & 3826 & 3826 \\
\hline \hline
\end{tabular}

Note: Selling prices are unit values of maize grain sales taken from the household survey Trabalho de Inquérito Agrícola (2002, 2003, 2005, 2006 and 2008). Columns (1) and (2) are restricted to households with location coordinates, column (3) and (4) uses primary sampling unit to extend the household coverage data, and column (5) and (6) exploit districts to extend the household coverage data. Household area is agricultural land cultivated with permanent and annual crops and fallow land. Covariates are gender, age and education of the household head, and household size. Age and household size are in natural logarithms. Standard errors clustered by district are in parentheses below the coefficient. ${ }^{*} p<0.10,{ }^{* *} p<0.05,{ }^{* * *} p<0.01$.

Estimation results on heterogeneity of impacts on selling prices by farmers' wealth, where wealth is approximated by household area size and household livestock, are presented in Table 5a. The estimation results indicate an insignificant impact for larger household area sizes, but a significant impact for households with larger livestock herds. Heterogeneity in impacts is not supported by the area estimations. However, households with large livestock herds experience a very much reduced or no negative impact of mobile phones. It is not fully clear what explains the difference in livestock and area heterogeneity: possibly, differences in holding sizes have little relationship with liquidity constraints, while larger livestock herds do relax liquidity constraints. The threshold size of the third tercile is 0.54 tropical livestock units which is equivalent to 5.4 goats or 54 chicken. The livestock heterogeneity only shows if sufficient classes are identified.

Estimation results on heterogeneity of farmer selling prices by educational attainment, presented in Table 5b, show an insignificant impact for 'any formal education'. Note that 'any formal education' also includes 'knows how to read and write' on top of all formal education starting at grade 1 . The hypothesis that high levels of education mitigates the negative impact 
of mobile phones is not supported by these estimation results. Different ways of classifying educational attainment did not change results fundamentally.

We consider a final explanation for the decrease in farm gate prices, which is inspired by the parallel trend figures (Figure 1a, $1 \mathrm{~b}$ and 2) and based on the likely difference in dissemination and active use of mobile phones among farmers and traders. We hypothesize that traders have a larger network of fellow traders with whom they communicate frequently, and thereby are quicker to adopt and use new communication technologies, compared to farmers: the average trader will have purchased and is using a mobile phone shortly after its introduction, while the average farmer is likely to lag a number of years behind. The pattern reflected in the parallel trends figures supports the sequential nature of take-up between these two groups (Figure 1a, 1b and 2): increases in margins tend to start quickly, even slightly before the introduction of mobile phones, as traders move around between markets. The increase in margins is large in the first years after mobile phone introduction, but after a few years gets smaller. This pattern is mirrored in the development of the impact on producer prices and household selling prices: during the first years after introduction the reduction is large, but after a few years this reduction becomes smaller. Formal tests on the difference in (maximum) impact shortly after introduction and a long time after introduction (year 5 or year 6) support this hypothesis.

\section{Summary and conclusion}

In this study we investigate if the introduction of mobile phones in Mozambique has brought a welfare gain to farmers or traders. We analyze household maize selling prices, producer prices, market prices, and the 'within market' margins between producer and market prices. The evidence supports increases in margins and decreases in producer prices and household selling prices that vary from $14 \%$ to $22 \%$. Our estimation results are robust to several threats. To 
answer the question raised in the title: the evidence does not support less asymmetric information and increased trader competition, but rather the reverse. The benefits from mobile phones accrue to traders, rather than to farmers, at least in the short run.

Despite several studies with a positive farmers' impact (Jensen, 2007; Svensson and Yanagizawa, 2009; Goyal, 2010), various other authors find only a weakly positive or insignificant impact of the introduction of mobile phones on received prices, farmers' welfare and behavior (Muto and Yamano, 2009; Fafchamps and Minten, 2012; Tadesse and Bahiigwa, 2015; Aker and Ksoll, 2016). What exactly determines if farmers or traders benefit from improved information? Virtually none of the earlier studies explores the underlying causes of impacts. In this study we find the significant positive impact of traders' margins are negatively correlated with the degree of competition, approximated by network or population density, and positively correlated with long-distance trade opportunities, approximated by the difference with terminal markets prices. We find some support for the claim that traders expanded their catchment area after the introduction of mobile phones. We investigated several circumstances that potentially influence the reduction in prices paid to farmers. We find support for correlation with household wealth, approximated by household livestock: wealthier households experience a very much reduced drop in prices. However, we find no support for a reduced drop in prices for higher educated household heads. Finally, the evidence supports differences in take-up that diminish over time, which suggests that traders are faster, and more proficient and skillful in exploiting mobile phones, while farmers lag behind. A delayed take-up by farmers leads to increases in traders' margins and reductions in producer prices shortly after the introduction of mobile phones that shrink over the years. 


\section{References}

Abdula, D.C., 2005, 'Improving Maize Marketing And Trade Policies To Promote Household Food Security In Southern Mozambique', thesis submitted for the degree of Master of science, Department of Agricultural Economics, Michigan State University.

Aggarwal, S. E. Francis and J. Robinson, 2018,'Grain Today, Gain Tomorrow: Evidence from a Storage Experiment with Savings Clubs in Kenya', Journal of Development Economics, 134, 1-15.

Aker, J.C., 2010, 'Information for Markets Near and Far: Mobile Phones and Agricultural Markets in Niger', American Economic Journal: Applied Economics, 2, 3, 46-59.

Aker, J.C. and M. Fafchamps, 2014, 'Mobile Phone Coverage and Producer Markets: Evidence from West Africa', World Bank Economic Review, 29, 2, 262-292.

Aker, J.C. and C. Ksoll, 2016, 'Can mobile phones improve agricultural outcomes? Evidence from a randomized experiment in Niger', Food Policy, 60, 44-51.

Akerlof, G.A., 1970, 'The Market for "Lemons": Quality Uncertainty and the Market Mechanism', The Quarterly Journal of Economics, 84, 3, 488-500.

Atkin, D. and D. Donaldson, 2015, 'Who's Getting Globalized? The Size and Implications of Intra-national Trade Costs', National Bureau of Economic Research, w21439.

Autor, D.H., 2003, 'Outsourcing at Will: The Contribution of Unjust Dismissal Doctrine to the Growth of Employment Outsourcing', Journal of Labor Economics, 2003, 21, 1.

Bertrand, M., E. Duflo and S. Mullainathan, 2004, 'How much should we trust difference-indifferences estimates?', Quarterly Journal Of Economics, 119, 1, 249-275.

Burke, M., L. Falcao Bergquist, and E. Miguel, 2019, 'Sell Low and Buy High: Arbitrage and Local Price Effects in Kenyan Markets', The Quarterly Journal of Economics, 134, 2, $785-842$.

Casaburi, L., R. Glennerster and T. Suri, 2013, 'Rural Roads and Intermediated Trade: 
Regression Discontinuity Evidence from Sierra Leone', unpublished;

Casaburi, L. and T. Reed, 2016, 'Competition and Interlinkages in Agricultural Markets: An experimental Approach', unpublished;

de Chaisemartin, C. and X. d'Haultfœulle, 2020, 'Tow-Way Fixed Effects Estimators with Heterogenous Treatment Effects', American Economic Review, 110, 9, 2964-2996.

Courtois, P. and Subervie, J., 2015, 'Farmer Bargaining Power and Market Information Services', American Journal of Agricultural Economics, 97, 3, 953-977.

Dillon, B. and C. Dambro, 2017, 'How Competitive are Crop Markets in Sub-Saharan Africa?, American Journal of Agricultural Economics, 99, 5, 1344-1361.

Fafchamps, M., and R.Vargas Hill, 2005, 'Selling at the Farm-gate or Travelling to the Market, American Journal of Agricultural Economics, 87, 3, August, 717-734.

Fafchamps, M., E.Gabre-Madhin and B.Minten, 2005, 'Increasing returns and market efficiency in agricultural trade', Journal of Development Economics, 78, 406-442.

Fafchamps, M. and B. Minten, 2012, 'Impact of SMS-Based Agricultural Information on Indian Farmers', World Bank Economic Review, 27, February, 1-32.

Falcao Bergquist, L. and M. Dinerstein, 2020, American Economic Review, 110, 12, 37053747.

Goodman-Bacon, A., 2018, 'Difference in Difference with Variation in Treatment Timing', NBER, wp25018, Cambridge.

Goyal, A., 2010, 'Information, Direct Access to Farmers and Rural Market Performance in Central India', American Economic Journal: Applied Economics, 2 (July), 22-45.

Jakiela, P., 2021, 'Simple Diagnostics for Two-Way Fixed Effects', Cornell University, working paper.

Jacoby, H.G. and B. Minten, 2009, 'On measuring the Benefits of Lower Transport Costs', Journal of Development Economics, 89, 1, 28-38. 
Jensen, R., 2007, 'The Digital Provide: Information (Technology), Market Performance, and Welfare in the South Indian Fisheries Sector', Quarterly Journal of Economics, 72, 3, 879-924.

Jensen, R.T, 2010, 'Information, efficiency, and welfare in agricultural markets', Agricultural Economics, 41, S1, 203-216.

Kaminski, J., L. Christiaensen and C.L.Gilbert, 2016, 'Seasonality in Local Food Prices and Consumption: Evidence from Tanzania', Oxford Economic Papers, 68, 3, 736-757.

Minten, B. and S.Kyle, 1999, 'The effect of Distance and Road Quality on Food Collection, Marketing Margins, and Traders' Wages: Evidence from the Former Zaire', Journal of Development Economics, 60, 467-495.

Muto, M. and T. Yamano, 2009, 'The Impact of Mobile Phone Coverage Expansion on Market Participation: Panel Data Evidence from Uganda', World Development, 37,12, 1887-1896.

Nakasone, E. 2013, 'The Role of Price Information in Agricultural Markets: Experimental Evidence from Rural Peru', Selected Paper prepared for presentation at the Agricultural \& Applied Economics Association's 2013 AAEA \& CAES Joint Annual Meeting, Washington, DC.

Rosenbaum, P.R. and D. B. Rubin, 1985, 'Constructing a Control Group Using Multivariate Matched Sampling Methods That Incorporate the Propensity Score', The American Statistician, 39, 1, 33-38.

Sitko, N.J and T.S.Jayne, 2014,'Explotative Briefcase Businessmen, Parasites, and other Myths and Legends: Assembly Traders and the Performance of Maize Markets in Eastern and Southern Africa', World Development, 54, 56-67.

Stigler, G, 1961, 'The Economics of Information', Journal of Political Economy, 69, 213-225. Svensson, J. and D.Yanagizawa, 2009, 'Getting Prices Right: The Impact of the Market 
Information Service in Uganda', Journal of the European Economic Association, 7, $2-3,435-445$.

Tadesse, G. and G. Bahiigwa, 2015, 'Mobile Phones and Farmers' Marketing Decisions in Ethiopia', World Development, 68, 296-307.

Tschirley, D., D. Abdula and M.T.Weber, 2006, ‘Toward Improved Maize Marketing and Trade Policies to Promote Household Food Security in Central and Southern Mozambique', Research Report 60E, Ministry of Agriculture, Directorate of Economics, Republic of Mozambique.

De Vletter, F and E. Polana, 2001, 'Female Itinerant Maize Traders in Southern Mozambique:

A Study of a Higher-End Informal Sector Activity and Its Potential for Poverty Reduction', ILO-SAMAT discussion paper 17.

Zant, W., 2019, 'Mobile Phones and Mozambique Traders: What is the Size of Reduced Search Costs and Who Benefits?', Tinbergen Discussion Paper 19-047/V, Tinbergen Institute, Amsterdam.

Zant, W., 2021, 'Measuring Trade Cost Reductions through a New Bridge in Mozambique: Who Benefits from Transport Infrastructure?', Journal of African Economies, ejab018, https://doi.org/10.1093/jae/ejab018.

Zavale, H., 2014. 'Analysis of price incentives and disincentives for maize in the Republic of Mozambique for the time period 2005-2013', MAFAP, FAO, Rome. 


\section{Appendix}

\section{Market price data}

Table A1 Availability of weekly price data by market

\begin{tabular}{lccccccc}
\hline \hline Market & $\begin{array}{c}\text { north / } \\
\text { south of } \\
\text { Zambezi }\end{array}$ & $\begin{array}{c}\text { producer } \\
\text { price }\end{array}$ & $\begin{array}{c}2 \\
\text { market } \\
\text { price }\end{array}$ & $\begin{array}{c}3 \\
\text { combined }\end{array}$ & $\begin{array}{c}4 \\
\text { trading } \\
\text { season }\end{array}$ & $\begin{array}{c}5 \\
\text { missing } \\
\text { in \% }\end{array}$ & $\begin{array}{c}6 \\
\text { mobile } \\
\text { phone } \\
\text { (in } \% \text { of 3) }\end{array}$ \\
\hline Alto Molocue & $\mathrm{N}$ & 27 & 198 & 26 & 24 & $96.2 \%$ & $0 \%$ \\
Angoche & $\mathrm{N}$ & 49 & 127 & 49 & 48 & $92.8 \%$ & $0 \%$ \\
Angonia & $\mathrm{N}$ & 322 & 346 & 321 & 241 & $52.7 \%$ & $61.3 \%$ \\
Cuamba & $\mathrm{N}$ & 299 & 338 & 289 & 196 & $57.4 \%$ & $90.7 \%$ \\
Mocuba & $\mathrm{N}$ & 169 & 296 & 138 & 104 & $79.6 \%$ & $0 \%$ \\
Monapo & $\mathrm{N}$ & 146 & 157 & 145 & 120 & $78.6 \%$ & $0 \%$ \\
Montepuez & $\mathrm{N}$ & 180 & 231 & 172 & 122 & $74.6 \%$ & $70.3 \%$ \\
Mutarara & $\mathrm{N}$ & 183 & 360 & 173 & 127 & $74.5 \%$ & $15.6 \%$ \\
Ribaue & $\mathrm{N}$ & 159 & 260 & 149 & 129 & $78.0 \%$ & $28.1 \%$ \\
\hline Chimoio & $\mathrm{S}$ & 535 & 568 & 532 & 363 & $21.5 \%$ & $90.4 \%$ \\
Chokwe & $\mathrm{S}$ & 20 & 449 & 20 & 19 & $97.1 \%$ & $25.0 \%$ \\
Gorongosa & $\mathrm{S}$ & 344 & 350 & 340 & 229 & $49.9 \%$ & $99.4 \%$ \\
Manica & $\mathrm{S}$ & 545 & 559 & 544 & 374 & $19.8 \%$ & $84.0 \%$ \\
Massinga & $\mathrm{S}$ & 81 & 413 & 78 & 74 & $88.5 \%$ & $2.6 \%$ \\
Nhamathanda & $\mathrm{S}$ & 70 & 70 & 65 & 44 & $90.4 \%$ & $100 \%$ \\
\hline \hline
\end{tabular}

Note: The data span from July 1997 to December 2009. Column 3, combined, shows the number of market-date observations with both producer and market prices ( $\mathrm{pf}>0, \mathrm{pm}>0$ ). Column 4 is those observations in column 3 that are in the trading season, from March to October. Column 5, missings in \%, expresses the complement of column 3 - the number of non-available or missing data - in terms of the maximum potentially available observations for each market (=total number of weeks). Column 6, mobile phone, shows the share of market-date observations with mobile phone coverage.

Table A2 Market price data by mobile phone coverage and year

\begin{tabular}{lccccccccccccc}
\hline \hline & $\mathbf{9 7}$ & $\mathbf{9 8}$ & $\mathbf{9 9}$ & $\mathbf{0 0}$ & $\mathbf{0 1}$ & $\mathbf{0 2}$ & $\mathbf{0 3}$ & $\mathbf{0 4}$ & $\mathbf{0 5}$ & $\mathbf{0 6}$ & $\mathbf{0 7}$ & $\mathbf{0 8}$ & $\mathbf{0 9}$ \\
\hline Without & 78 & 125 & 214 & 152 & 132 & 95 & 94 & 45 & 26 & 0 & 0 & 0 & 0 \\
With & 0 & 0 & 0 & 66 & 90 & 98 & 164 & 240 & 245 & 200 & 258 & 284 & 302 \\
Total & 78 & 125 & 214 & 218 & 222 & 193 & 258 & 285 & 271 & 200 & 258 & 284 & 302 \\
\hline \hline
\end{tabular}

Source: Authors' calculations based on data from Sistema de Informação de Mercados Agrícolas de Moçambique and the Ministry of Transport and Communication of Mozambique.

Note: The table reports total the number of weekly observations by year with both producer and market prices. With and without refers to with and without mobile phone coverage.

Table A3 Are missing observations correlated with mobile phone coverage? (DiD-OLS)

\begin{tabular}{|c|c|c|c|c|}
\hline \multicolumn{5}{|c|}{ Dependent variable: missing observations (indicator variable) } \\
\hline $\begin{array}{l}\text { Sample } \\
\text { Variables }\end{array}$ & $1997-2009$ & $1999-2006$ & excluding Nov-Feb & $\begin{array}{c}\text { 1999-2006, } \\
\text { excluding Nov-Feb }\end{array}$ \\
\hline Mobile phone & $0.034^{* *}(0.015)$ & $0.008(0.016)$ & $0.045^{* *}(0.018)$ & $0.019(0.020)$ \\
\hline Markets & Yes & Yes & yes & Yes \\
\hline year-month & Yes & Yes & yes & Yes \\
\hline R2 & 0.354 & 0.365 & 0.350 & 0.383 \\
\hline Observations & 10170 & 6255 & 6825 & 4200 \\
\hline
\end{tabular}

Note: The full sample means the 15 markets identified in the estimations, markets where both producer and market prices are recorded (and hence excludes markets that only exclusively record market prices). Robust standard errors are in parentheses next to the coefficient. ${ }^{*} p<0.10,{ }^{* *} p<0.05,{ }^{* * *} p<0.01$. 
Table A4 Lee bounds for impacts of mobile phone coverage

\begin{tabular}{lcc|cc|cc}
\hline \hline dependent variable: & \multicolumn{2}{c|}{$\ln ($ margin $)$} & \multicolumn{2}{c|}{$\ln ($ producer price $)$} & \multicolumn{2}{c}{$\ln ($ market price $)$} \\
$\ln \left(\mathrm{p}_{\mathrm{m}} / \mathrm{p}_{\mathrm{f}}\right)$ & \multicolumn{2}{c|}{$\ln \left(\mathrm{p}_{\mathrm{f}}\right)$} & \multicolumn{2}{c}{$\ln \left(\mathrm{p}_{\mathrm{m}}\right)$} \\
Sample & $1997-2009$ & $1997-2007$ & $1997-2009$ & $1997-2007$ & $1997-2009$ & $1997-2007$ \\
\hline \# of observations & 10170 & 8595 & 10170 & 8595 & 10170 & 8595 \\
\# of selected observations & 3041 & 2453 & 3041 & 2453 & 3041 & 2453 \\
trimming proportion & 0.3631 & 0.3518 & 0.3631 & 0.3518 & 0.3631 & 0.3518 \\
Lower & -0.077 & -0.069 & 0.022 & -0.077 & 0.078 & -0.015 \\
& $(0.008)$ & $(0.009)$ & $(0.022)$ & $(0.021)$ & $(0.021)$ & $(0.019)$ \\
Upper & 0.111 & 0.125 & 0.574 & 0.370 & 0.568 & 0.378 \\
& $(0.010)$ & $(0.011)$ & $(0.025)$ & $(0.023)$ & $(0.023)$ & $(0.022)$ \\
95\% confidence intervals & -0.090 & -0.084 & -0.015 & -0.111 & -0.044 & -0.046 \\
& 0.127 & 0.143 & 0.614 & 0.409 & 0.605 & 0.352 \\
\hline \hline
\end{tabular}

Note: Lee bounds offer an estimator for treatment effect bounds if selection into treatment is not random. In our case, selection into treatment (mobile phone coverage) may have improved collection and recording of price data.

\section{Household survey data}

Table A5 Household survey data: sample and mobile phone coverage by year

\begin{tabular}{|c|c|c|c|c|c|c|}
\hline & 2002 & 2003 & 2005 & 2006 & 2008 & all years \\
\hline \multicolumn{7}{|l|}{ Total number of households } \\
\hline & 4908 & 4949 & 6150 & 6248 & 5968 & 28223 \\
\hline \multicolumn{7}{|l|}{ Farm households } \\
\hline & 4055 & 4085 & 4942 & 4883 & 4756 & 22721 \\
\hline \multicolumn{7}{|c|}{ Unit values of household maize sales } \\
\hline & 915 & 828 & 982 & 831 & 272 & 3828 \\
\hline \multicolumn{7}{|c|}{ Households with unit values \& coordinates } \\
\hline \multicolumn{7}{|c|}{ A. sample: households with coordinates } \\
\hline no mobile phone coverage & 276 & 697 & 204 & 118 & 41 & 1336 \\
\hline mobile phone coverage & 41 & 106 & 207 & 139 & 118 & 611 \\
\hline total sample & 317 & 803 & 411 & 257 & 159 & 1947 \\
\hline not in sample & 598 & 25 & 571 & 574 & 113 & 1881 \\
\hline \multicolumn{7}{|c|}{ B. sample: hh with coordinates + hhs in PSU with coordinates for at least one $h$ h in PSU } \\
\hline no mobile phone coverage & 418 & 697 & 279 & 161 & 46 & 1601 \\
\hline mobile phone coverage & 66 & 106 & 301 & 204 & 147 & 824 \\
\hline total sample & 484 & 803 & 580 & 365 & 193 & 2425 \\
\hline not in sample & 431 & 25 & 402 & 466 & 79 & 1403 \\
\hline \multicolumn{7}{|l|}{ C. sample: all households } \\
\hline no mobile phone coverage & 804 & 714 & 522 & 370 & 46 & 2456 \\
\hline mobile phone coverage & 111 & 114 & 460 & 461 & 226 & 1372 \\
\hline total sample & 915 & 828 & 982 & 831 & 272 & 3828 \\
\hline not in sample & 0 & 0 & 0 & 0 & 0 & 0 \\
\hline \multicolumn{7}{|c|}{ share of observations in total household selling price observations } \\
\hline sample A & $34,6 \%$ & $97,0 \%$ & $41,9 \%$ & $30,9 \%$ & $58,5 \%$ & $50,9 \%$ \\
\hline sample B & $52,9 \%$ & $97,0 \%$ & $59,1 \%$ & $43,9 \%$ & $71,0 \%$ & $63,3 \%$ \\
\hline sample C & $100,0 \%$ & $100,0 \%$ & $100,0 \%$ & $100,0 \%$ & $100,0 \%$ & $100,0 \%$ \\
\hline
\end{tabular}

Source: Authors' calculations based on data from the household survey Trabalho de Inquérito Agrícola (2002, 2003, 2005, 2006 and 2008).

Note: Farm households are households with agriculture as their main activity. Sample A: mobile phone coverage if households are located less than $35 \mathrm{~km}$ from a mobile phone tower; Sample B: mobile phone coverage if households are located less than $35 \mathrm{~km}$ from a mobile phone tower plus households in the primary sampling unit (village, community) if at least one household in the PSU has mobile phone coverage; and Sample C: as sample B, plus households in the district if the average mobile phone coverage in the district is $\geq 0.5$. 
Table A6 Share of households growing maize

\begin{tabular}{l|cccccc}
\hline \hline & \multicolumn{6}{|c}{ survey year } \\
share of households & 2002 & 2003 & 2005 & 2006 & 2008 & 2012 \\
growing maize in \% & & & & & \\
\hline Niassa & 99.6 & 99.6 & 96.1 & 96.5 & 98.3 & 94.0 \\
Cabo Delgado & 82.4 & 79.3 & 81.4 & 77.5 & 83.5 & 81.0 \\
Nampula & 65.4 & 69.6 & 68.4 & 63.4 & 59.1 & 66.2 \\
Zambezia & 77.8 & 77.0 & 73.8 & 71.2 & 68.8 & 68.2 \\
Tete & 91.8 & 93.2 & 92.1 & 96.6 & 97.2 & 89.3 \\
Manica & 98.1 & 96.6 & 94.7 & 97.1 & 94.7 & 95.2 \\
Sofala & 91.8 & 93.6 & 93.8 & 91.2 & 89.7 & 79.2 \\
Inhambane & 88.3 & 84.5 & 81.1 & 84.6 & 86.1 & 78.5 \\
Gaza & 95.7 & 96.2 & 91.1 & 93.9 & 94.6 & 92.9 \\
Maputo & 94.5 & 91.8 & 83.7 & 80.7 & 85.9 & 78.1 \\
Mozambique & 86.9 & 87.2 & 84.5 & 83.8 & 84.3 & 80.8 \\
N & 4908 & 4935 & 6149 & 6248 & 5968 & 6744 \\
\hline \hline
\end{tabular}

source: Trabalho de Inquérito Agrícola (TIA, various survey years)

Table A7 Share of maize growing households selling maize grain

\begin{tabular}{|c|c|c|c|c|c|c|}
\hline \multirow[b]{2}{*}{$\begin{array}{l}\text { share of maize } \\
\text { growing households } \\
\text { selling maize grain } \\
\text { on the market in \% }\end{array}$} & \multicolumn{6}{|c|}{ survey year } \\
\hline & 2002 & 2003 & 2005 & 2006 & 2008 & 2012 \\
\hline Niassa & 37.7 & 29.0 & 21.3 & 26.1 & 23.5 & 16.1 \\
\hline Cabo Delgado & 28.4 & 20.9 & 23.3 & 17.7 & 18.8 & 13.9 \\
\hline Nampula & 29.6 & 26.3 & 26.1 & 24.4 & 30.7 & 19.7 \\
\hline Zambezia & 45.6 & 44.0 & 38.7 & 37.1 & 42.3 & 34.6 \\
\hline Tete & 32.1 & 18.3 & 23.9 & 18.6 & 15.9 & 13.1 \\
\hline Manica & 26.2 & 23.9 & 24.9 & 22.9 & 18.3 & 22.7 \\
\hline Sofala & 19.4 & 23.3 & 22.3 & 24.2 & 22.6 & 15.9 \\
\hline Inhambane & 4.5 & 2.9 & 4.4 & 4.6 & 7.8 & 7.1 \\
\hline Gaza & 9.7 & 4.1 & 3.8 & 3.9 & 4.4 & 2.3 \\
\hline Maputo & 10.2 & 3.4 & 8.0 & 7.9 & 6.9 & 5.5 \\
\hline Mozambique & 25.0 & 20.0 & 20.3 & 18.4 & 18.8 & 15.3 \\
\hline $\mathrm{N}$ & 4265 & 4305 & 5195 & 5237 & 5029 & 5450 \\
\hline
\end{tabular}

source: Trabalho de Inquérito Agrícola (TIA, various survey years)

Table A8 Destination of maize grain transactions (sold to whom?)

\begin{tabular}{|c|c|c|c|c|c|c|}
\hline \multirow[b]{2}{*}{$\begin{array}{l}\text { share in } \% \text { of maize } \\
\text { grain transactions to }\end{array}$} & \multicolumn{6}{|c|}{ survey year } \\
\hline & 2002 & 2003 & 2005 & 2006 & 2008 & $2011^{*}$ \\
\hline Neighbor & 11.9 & & 21.3 & & & \\
\hline itinerant trader & 55.4 & & 54.4 & & & \\
\hline client in the market & 13.5 & & 15.2 & & & \\
\hline Other & 19.3 & & 9.1 & & & \\
\hline $\mathrm{N}$ & 1053 & & 1018 & & & \\
\hline Neighbor & 9.2 & & 18.4 & & & 12.8 \\
\hline itinerant trader & 55.5 & & 57.4 & & & 40.2 \\
\hline client in the market & 14.3 & & 14.4 & & & 25.4 \\
\hline Other & 22.0 & & 10.8 & & & 21.6 \\
\hline $\mathrm{N}$ & 732 & & 755 & & & 595 \\
\hline
\end{tabular}

source: Trabalho de Inquérito Agrícola (TIA, various survey years)

* The TIA survey 2011 covers only 5 provinces (Nampula, Zambezia, Tete, Manica, Sofala). The lower part of the table therefore repeats the 2002 and 2005 information restricted to these provinces. 
Table A9 Seasonality in maize grain sales (sold when?)

\begin{tabular}{|c|c|c|c|c|c|c|}
\hline \multirow[b]{2}{*}{$\begin{array}{l}\text { share in } \% \text { of maize grain } \\
\text { transactions by month }\end{array}$} & \multicolumn{6}{|c|}{ survey year } \\
\hline & 2002 & 2003 & 2005 & 2006 & 2008 & $2011^{*}$ \\
\hline January & & & 1.0 & & & 1.5 \\
\hline February & & & 2.9 & & & 1.0 \\
\hline March & & & 2.9 & & & 2.4 \\
\hline April & & & 5.0 & & & 3.7 \\
\hline May & & & 4.6 & & & 4.5 \\
\hline June & & & 14.7 & & & 12.4 \\
\hline July & & & 18.9 & & & 14.3 \\
\hline August & & & 22.7 & & & 18.7 \\
\hline September & & & 15.9 & & & 21.5 \\
\hline October & & & 8.7 & & & 14.3 \\
\hline November & & & 2.1 & & & 3.9 \\
\hline December & & & 0.7 & & & 1.9 \\
\hline $\mathrm{N}$ & & & 1018 & & & 595 \\
\hline
\end{tabular}

source: Trabalho de Inquérito Agríxcola (TIA, various survey years)

* The TIA survey 2011 covers only 5 provinces (Nampula, Zambezia, Tete, Manica, Sofala).

Table A10 Holding size and maize sales

\begin{tabular}{|c|c|c|c|c|c|c|}
\hline \multirow[b]{2}{*}{$\begin{array}{l}\text { medium holding } \operatorname{size}^{*}(\% \text { in } \\
\text { total }) \text {, by selling and non- } \\
\text { selling households }\end{array}$} & \multicolumn{6}{|c|}{ survey year } \\
\hline & 2002 & 2003 & 2005 & 2006 & 2008 & 2011 \\
\hline Niassa & $0.0 ; 0.4$ & & $1.4 ; 3.5$ & & $1.8 ; 0.8$ & \\
\hline Cabo Delgado & $5.1 ; 1.8$ & & $8.9 ; 7.0$ & & $1.2 ; 2.7$ & \\
\hline Nampula & $3.4 ; 3.3$ & & $4.3 ; 5.0$ & & $0.7 ; 0.3$ & \\
\hline Zambezia & $2.7 ; 2.1$ & & $3.1 ; 2.0$ & & $0.9 ; 1.0$ & \\
\hline Tete & $30.1 ; 26.2$ & & $43.4 ; 27.0$ & & $42.9 ; 17.3$ & \\
\hline Manica & $13.8 ; 15.2$ & & $17.6 ; 15.9$ & & $7.7 ; 6.4$ & \\
\hline Sofala & $17.6 ; 12.3$ & & $12.6 ; 10.6$ & & $6.0 ; 6.1$ & \\
\hline Inhambane & $41.2 ; 12.1$ & & $23.8 ; 16.3$ & & $27.8 ; 3.8$ & \\
\hline Gaza & $51.0 ; 32.1$ & & $66.7 ; 43.8$ & & $23.1 ; 25.7$ & \\
\hline Maputo & $42.2 ; 23.8$ & & $50.0 ; 27.3$ & & $31.3 ; 16.5$ & \\
\hline Mozambique & $13.7 ; 13.2$ & & $16.6 ; 19.0$ & & $9.6 ; 9.6$ & \\
\hline
\end{tabular}

source: Trabalho de Inquérito Agrícola (TIA, various survey years)

* Small sized farms are less than 1 ha $(<1)$; medium sized farms are between 1 and 2 ha $(\geq 1$ and $<2)$.

\section{Table A11 Storage facilities and maize sales}

\begin{tabular}{|c|c|c|c|c|c|c|}
\hline \multirow[b]{2}{*}{$\begin{array}{l}\text { improved granaries available } \\
\text { (in \%), by selling and non- } \\
\text { selling households }\end{array}$} & \multicolumn{6}{|c|}{ survey year } \\
\hline & 2002 & 2003 & 2005 & 2006 & 2008 & $2011^{*}$ \\
\hline Niassa & & & $11.6 ; 14.1$ & & & \\
\hline Cabo Delgado & & & $36.6 ; 30.9$ & & & \\
\hline Nampula & & & $10.0 ; 10.8$ & & & $29.8 ; 21.2$ \\
\hline Zambezia & & & $22.0 ; 12.7$ & & & $29.7 ; 11.8$ \\
\hline Tete & & & $29.6 ; 23.0$ & & & $33.8 ; 24.3$ \\
\hline Manica & & & $31.1 ; 28.1$ & & & $40.4 ; 31.2$ \\
\hline Sofala & & & $11.7 ; 7.2$ & & & $44.8 ; 33.5$ \\
\hline Inhambane & & & $4.8 ; 9.3$ & & & \\
\hline Gaza & & & $20.0 ; 16.4$ & & & \\
\hline Maputo & & & $40.0 ; 22.1$ & & & \\
\hline Mozambique & & & $22.5 ; 17.3$ & & & $36.3 ; 24.4$ \\
\hline
\end{tabular}

source: Trabalho de Inquérito Agrícola (TIA, various survey years)

* The TIA survey 2011 covers only 5 provinces (Nampula, Zambezia, Tete, Manica, Sofala). 
Table A12 Educational attainment, literacy and age of agricultural and non-agricultural household heads

\begin{tabular}{|c|c|c|c|c|c|c|}
\hline \multirow[b]{2}{*}{ Educational attainment } & \multicolumn{6}{|c|}{ survey year } \\
\hline & 2002 & 2003 & 2005 & 2006 & 2008 & 2011* \\
\hline $\begin{array}{l}\text { farm household } \\
\text { no education }\end{array}$ & 44.9 & 47.2 & 42.8 & 51.2 & 47.3 & 39.5 \\
\hline 1-6 years & 48.6 & 44.6 & 50.1 & 44.2 & 44.0 & 48.8 \\
\hline $7-12$ years & 6.6 & 8.2 & 7.1 & 4.7 & 8.7 & 11.7 \\
\hline number of observations & 4052 & 4082 & 4941 & 4883 & 4756 & 995 \\
\hline \multicolumn{7}{|l|}{ non-farm household } \\
\hline no education & 21.2 & 19.4 & 20.5 & 23.5 & 16.1 & 33.5 \\
\hline $1-6$ years & 56.2 & 53.1 & 54.1 & 49.3 & 50.3 & 39.8 \\
\hline $7-12$ years & 22.7 & 27.5 & 25.4 & 27.1 & 33.6 & 26.7 \\
\hline number of observations & 851 & 850 & 1208 & 1365 & 1212 & 191 \\
\hline \multicolumn{7}{|l|}{ Literacy } \\
\hline \multicolumn{7}{|l|}{ farm household } \\
\hline Yes & 44.9 & 47.2 & 40.7 & 43.6 & 45.7 & 50.4 \\
\hline No & 55.1 & 52.8 & 59.3 & 56.4 & 54.3 & 49.7 \\
\hline number of observations & 4052 & 4082 & 4941 & 4883 & 4756 & 995 \\
\hline \multicolumn{7}{|l|}{ non-farm household } \\
\hline Yes & 78.8 & 80.6 & 71.6 & 74.4 & 80.6 & 63.9 \\
\hline No & 21.2 & 19.4 & 28.4 & 25.6 & 19.4 & 36.1 \\
\hline number of observations & 851 & 850 & 1208 & 1365 & 1212 & 191 \\
\hline \multicolumn{7}{|l|}{ Age (average / median) } \\
\hline farm household & $44.4(43)$ & $45.4(44)$ & $46.3(45)$ & $45.2(44)$ & $44.7(43)$ & $44.5(43)$ \\
\hline number of observations & 4048 & 4085 & 4939 & 4883 & 4756 & 995 \\
\hline non-farm household & $41.4(40)$ & $43.2(41)$ & $43.7(42)$ & $42.3(40)$ & $41.6(40)$ & $43.4(41)$ \\
\hline number of observations & 851 & 849 & 1208 & 1364 & 1212 & 190 \\
\hline
\end{tabular}

source: Trabalho de Inquérito Agrícola (TIA, various survey years)

* The TIA survey 2011 covers only 5 provinces (Nampula, Zambezia, Tete, Manica, Sofala).

\section{Analysis of staggered intervention design}

Table A13 Assessing homogeneity of impact: residualized outcome versus residualized intervention

\begin{tabular}{|c|c|c|}
\hline dependent variable & $\begin{array}{c}\text { margin } \\
\ln \left(p_{m} / p_{f}\right)\end{array}$ & $\begin{array}{l}\text { producer price } \\
\qquad \ln \left(p_{f}\right)\end{array}$ \\
\hline residualized intervention (a) & $\begin{array}{c}0.089 \\
(0.148)\end{array}$ & $\begin{array}{c}-0.253 \\
(0.335)\end{array}$ \\
\hline residualized intervention $\mathrm{x}$ mobile phone (b) & $\begin{array}{c}0.111 \\
(0.178)\end{array}$ & $\begin{array}{c}0.421 \\
(0.415)\end{array}$ \\
\hline mobile phone & $\begin{array}{c}-0.005 \\
(0.031)\end{array}$ & $\begin{array}{c}0.295 \\
(0.072)\end{array}$ \\
\hline Covariates & no & No \\
\hline $\mathrm{R}^{2}$ & 0.043 & 0.167 \\
\hline no. of observations & 110 & 110 \\
\hline Homogeneity $(b=0)$ & $\begin{array}{c}F(1,106): 0.37 \\
(0.5466)\end{array}$ & $\begin{array}{c}F(1,106): 1.03 \\
(0.3128)\end{array}$ \\
\hline
\end{tabular}

Note: The dependent variable is the residual from an estimation of margins (or producer prices) on market and year fixed effects. The residualized intervention is the residual from the estimation of the intervention variable on market and year fixed effects. The residualized intervention is split up by intervention and comparison group (Jakiela, 2021). Homogeneity is explored by testing equality of the slope for intervention and comparison observations. Under the hypothesis of homogenous impacts the table shows the F-statistic and in parentheses its associated p-value. 


\section{Impact estimations}

Table A14 Impact of mobile phones on prices and margins: full sample, DiD-OLS

\begin{tabular}{lcc|cc|cc}
\hline \hline dependent variable & \multicolumn{2}{c|}{$\ln ($ margin $)$} & \multicolumn{2}{c|}{$\ln ($ producer price $)$} & \multicolumn{2}{c}{$\ln ($ market price $)$} \\
& \multicolumn{2}{c|}{$\ln \left(\mathrm{p}_{\mathrm{m}} / \mathrm{p}_{\mathrm{f}}\right)$} & \multicolumn{2}{c|}{$\ln \left(\mathrm{p}_{\mathrm{f}}\right)$} & \multicolumn{2}{c|}{${ }^{*}$} \\
\hline mobile phone & $0.116^{* *}$ & $0.126^{* *}$ & $-0.132^{* *}$ & $-0.122^{* *}$ & -0.016 & 0.004 \\
& $(0.049)$ & $(0.048)$ & $(0.059)$ & $(0.053)$ & $(0.089)$ & $(0.083)$ \\
Covariates & No & Yes & no & yes & No & Yes \\
$\mathrm{R}^{2}$ & 0.495 & 0.501 & 0.847 & 0.848 & 0.854 & 0.857 \\
no. of observations & 3021 & 3021 & 3021 & 3021 & 3021 & 3021 \\
\hline \hline
\end{tabular}

Note: Maize price data are from July 1997 to December 2009 (source: SIMA). Estimations include market and year-month fixed effects, and control for market specific seasonality. Prices are deflated with the national consumer price index. Covariates are population size, district population density, elevation and distance to big cities, all in natural logarithms. Robust standard errors, clustered by market are in parentheses below the coefficients. ${ }^{*} p<0.10,{ }^{* *} p<0.05,{ }^{* * *} p<0.01$.

Table A15 Impact of mobile phones on prices and margins with annualized data

\begin{tabular}{lcc|cc|cc}
\hline \hline dependent variable & \multicolumn{2}{c|}{$\ln ($ margin $)$} & \multicolumn{2}{c|}{$\ln ($ producer price $)$} & \multicolumn{2}{c}{$\ln ($ market price $)$} \\
& \multicolumn{2}{c|}{$\ln \left(\mathrm{p}_{\mathrm{m}} / \mathrm{p}_{\mathrm{f}}\right)$} & \multicolumn{2}{c}{$\ln \left(\mathrm{p}_{\mathrm{f}}\right)$} & \multicolumn{2}{c}{$\ln \left(\mathrm{p}_{\mathrm{m}}\right)$} \\
\hline mobile phone & $0.158^{* * *}$ & $0.159^{* * *}$ & $-0.221^{* * *}$ & $-0.219^{* * *}$ & 0.002 & 0.010 \\
& $(0.047)$ & $(0.045)$ & $(0.047)$ & $(0.050)$ & $(0.145)$ & $(0.153)$ \\
Covariates & no & Yes & no & yes & no & yes \\
$\mathrm{R}^{2}$ & 0.574 & 0.585 & 0.796 & 0.797 & 0.786 & 0.800 \\
no. of observations & 110 & 110 & 110 & 110 & 110 & 110 \\
\hline \hline
\end{tabular}

Note: Annualized maize price data are from 1997 to 2009, calculated on the basis of the weekly data (source: SIMA). Estimations include market and year fixed effects. Prices are deflated with the national consumer price index. Covariates are population, elevation and distance to big cities, all in natural logarithms. Robust standard errors, clustered by market are in parentheses below the coefficients. ${ }^{*} p<0.10,{ }^{* *} p<0.05,{ }^{* * *} p<0.01$.

Table A16 Impact of mobile phones on prices and margins: 2000-2009, DiD-OLS

\begin{tabular}{|c|c|c|c|c|c|c|}
\hline \multirow{2}{*}{$\begin{array}{l}\text { dependent variable } \\
\text { mobile phone }\end{array}$} & \multicolumn{2}{|c|}{$\begin{array}{c}\ln (\operatorname{margin}) \\
\ln \left(\mathrm{p}_{\mathrm{m}} / \mathrm{p}_{\mathrm{f}}\right)\end{array}$} & \multicolumn{2}{|c|}{$\begin{array}{c}\ln (\text { producer price }) \\
\ln \left(\mathrm{p}_{\mathrm{f}}\right)\end{array}$} & \multicolumn{2}{|c|}{$\begin{array}{c}\ln (\text { market price }) \\
\ln \left(\mathrm{p}_{\mathrm{m}}\right)\end{array}$} \\
\hline & $\begin{array}{l}0.138^{* * *} \\
(0.045)\end{array}$ & $\begin{array}{l}0.145^{* * *} \\
(0.043)\end{array}$ & $\begin{array}{l}-0.162^{* *} \\
(0.066)\end{array}$ & $\begin{array}{l}-0.144^{* *} \\
(0.056)\end{array}$ & $\begin{array}{l}-0.024 \\
(0.091)\end{array}$ & $\begin{array}{c}0.000 \\
(0.076)\end{array}$ \\
\hline Covariates & no & Yes & no & yes & No & Yes \\
\hline $\operatorname{adj} R^{2}$ & 0.532 & 0.534 & 0.863 & 0.865 & 0.864 & 0.868 \\
\hline no. of observations & 2558 & 2558 & 2558 & 2558 & 2558 & 2558 \\
\hline
\end{tabular}

Note: See explanation in Note to Table A14. Estimations with varying starting and ending year (resp. 1997-2000 and 2005-2009, 16 samples) generated no reversals in the sign of the key coefficients (margin, producer price). Significance improved the later the starting year and ending year. The table reports the best result in terms of significance of the key coefficients. Other results available from the author.

Table A17 Impact of mobile phones on prices and margins: excluding Nov-Feb, DiD-OLS

\begin{tabular}{|c|c|c|c|c|c|c|}
\hline dependent variable & \multicolumn{2}{|c|}{$\begin{array}{c}\ln (\text { margin }) \\
\ln \left(\mathrm{p}_{\mathrm{m}} / \mathrm{p}_{\mathrm{f}}\right)\end{array}$} & \multicolumn{2}{|c|}{$\begin{array}{c}\ln (\text { producer price }) \\
\ln \left(\mathrm{p}_{\mathrm{f}}\right)\end{array}$} & \multicolumn{2}{|c|}{$\begin{array}{c}\ln (\text { market price }) \\
\ln \left(\mathrm{p}_{\mathrm{m}}\right)\end{array}$} \\
\hline mobile phone & $\begin{array}{l}0.173^{* * *} \\
(0.051)\end{array}$ & $\begin{array}{l}0.183^{* * *} \\
(0.049)\end{array}$ & $\begin{array}{c}-0.193^{* * *} \\
(0.059)\end{array}$ & $\begin{array}{l}-0.174^{* * *} \\
(0.051)\end{array}$ & $\begin{array}{l}-0.020 \\
(0.086)\end{array}$ & $\begin{array}{l}-0.009 \\
(0.075)\end{array}$ \\
\hline Covariates & No & Yes & no & yes & No & yes \\
\hline $\operatorname{adj} R^{2}$ & 0.523 & 0.525 & 0.836 & 0.838 & 0.837 & 0.840 \\
\hline no. of observations & 1808 & 1808 & 1808 & 1808 & 1808 & 1808 \\
\hline
\end{tabular}

Note: See explanation in Note to Table A14. Following the results of the estimations with varying samples the sample period is restricted to 2000-2009. 
Table A18 Impact of mobile phones on prices and margins: north, DiD-OLS

\begin{tabular}{|c|c|c|c|c|c|c|}
\hline dependent variable & \multicolumn{2}{|c|}{$\begin{array}{c}\ln (\operatorname{margin}) \\
\ln \left(\mathrm{p}_{\mathrm{m}} / \mathrm{p}_{\mathrm{f}}\right)\end{array}$} & \multicolumn{2}{|c|}{$\begin{array}{c}\ln (\text { producer price }) \\
\ln \left(\mathrm{p}_{\mathrm{f}}\right)\end{array}$} & \multicolumn{2}{|c|}{$\begin{array}{c}\ln (\text { market price }) \\
\ln \left(\mathrm{p}_{\mathrm{m}}\right)\end{array}$} \\
\hline mobile phone & $\begin{array}{l}0.094^{* * *} \\
(0.016)\end{array}$ & $\begin{array}{l}0.062^{* * *} \\
(0.017)\end{array}$ & $\begin{array}{c}-0.252^{* * *} \\
(0.040)\end{array}$ & $\begin{array}{c}-0.233^{* * *} \\
(0.055)\end{array}$ & $\begin{array}{l}-0.171^{* *} \\
(0.058)\end{array}$ & $\begin{array}{r}-0.158^{* * *} \\
(0.046)\end{array}$ \\
\hline Covariates & no & yes & no & yes & No & yes \\
\hline $\operatorname{adj} R^{2}$ & 0.571 & 0.580 & 0.889 & 0.889 & 0.903 & 0.886 \\
\hline no. of observations & 1342 & 1342 & 1342 & 1342 & 1342 & 1342 \\
\hline
\end{tabular}

Note: See explanation in Note to Table A14.

Table A19 Impact of mobile phones on prices and margins: south, DiD-OLS

\begin{tabular}{|c|c|c|c|c|c|c|}
\hline \multirow{2}{*}{$\begin{array}{l}\text { dependent variable } \\
\text { mobile phone }\end{array}$} & \multicolumn{2}{|c|}{$\begin{array}{c}\ln (\text { margin }) \\
\ln \left(\mathrm{p}_{\mathrm{m}} / \mathrm{p}_{\mathrm{f}}\right)\end{array}$} & \multicolumn{2}{|c|}{$\begin{array}{c}\ln (\text { producer price }) \\
\ln \left(\mathrm{p}_{\mathrm{f}}\right)\end{array}$} & \multicolumn{2}{|c|}{$\begin{array}{c}\ln (\text { market price }) \\
\ln \left(\mathrm{p}_{\mathrm{m}}\right)\end{array}$} \\
\hline & $\begin{array}{l}0.100^{* *} \\
(0.030)\end{array}$ & $\begin{array}{c}0.027 \\
(0.028)\end{array}$ & $\begin{array}{c}-0.157^{* *} \\
(0.059)\end{array}$ & $\begin{array}{c}-0.274^{\text {*** }} \\
(0.062)\end{array}$ & $\begin{array}{l}-0.056 \\
(0.080)\end{array}$ & $\begin{array}{c}-0.247^{* *} \\
(0.088)\end{array}$ \\
\hline Covariates & no & yes & no & yes & No & yes \\
\hline $\operatorname{adj} R^{2}$ & 0.590 & 0.614 & 0.892 & 0.906 & 0.890 & 0.909 \\
\hline no. of observations & 1465 & 1465 & 1465 & 1465 & 1465 & 1465 \\
\hline
\end{tabular}

Note: See explanation in Note to Table A14.

Table A20 Impact of mobile phones on household selling prices: DiD-OLS

\begin{tabular}{lcc|cc|cc}
\hline \hline dependent variable: $\ln ($ selling price) & $(1)$ & $(2)$ & $(3)$ & $(4)$ & $(5)$ & $(6)$ \\
\hline mobile phone & $-0.229^{* * *}$ & $-0.234^{* * *}$ & $-0.184^{* *}$ & $-0.188^{* *}$ & $-0.132^{* *}$ & $-0.132^{* *}$ \\
& $(0.076)$ & $(0.075)$ & $(0.071)$ & $(0.072)$ & $(0.056)$ & $(0.056)$ \\
year x province (binary) & Yes & Yes & yes & Yes & Yes & yes \\
primary sampling unit (binary) & Yes & Yes & yes & Yes & Yes & yes \\
Covariates & No & Yes & no & Yes & No & yes \\
$\mathrm{R}^{2}$ & 0.462 & 0.463 & 0.414 & 0.415 & 0.364 & 0.364 \\
no. of observations & 1947 & 1947 & 2425 & 2425 & 3828 & 3826 \\
\hline \hline
\end{tabular}

Note: Selling prices are unit values of maize grain sales taken from the household survey Trabalho de Inquérito Agrícola (2002, 2003, 2005, 2006 and 2008). Columns (1) and (2) are restricted to households with location coordinates. Columns (3) and (4) uses primary sampling units to extend the mobile phone coverage data, and columns (5) and (6) further extends this by exploiting district information. Covariates are gender, age and education of the household head, and household size (number of family members). Age and household size are in natural logarithms. Standard errors clustered by district are reported in parentheses below the coefficient. ${ }^{*} p<0.10,{ }^{* *} p<0.05,{ }^{* * *} p<0.01$.

Table A21 Impact of mobile phones on household selling prices: north, DiD-OLS,

\begin{tabular}{lcc|cc|cc}
\hline dependent variable: $\ln ($ selling price) & $(1)$ & $(2)$ & $(3)$ & $(4)$ & $(5)$ & $(6)$ \\
\hline mobile phone & $-0.238^{* *}$ & $-0.243^{* *}$ & $-0.137^{*}$ & $-0.141^{*}$ & -0.091 & -0.089 \\
& $(0.093)$ & $(0.092)$ & $(0.070)$ & $(0.071)$ & $(0.065)$ & $(0.066)$ \\
year x province (binary) & Yes & yes & yes & yes & yes & yes \\
primary sampling unit (binary) & Yes & yes & yes & yes & yes & yes \\
Covariates & No & yes & no & yes & no & yes \\
$\mathrm{R}^{2}$ & 0.419 & 0.420 & 0.382 & 0.382 & 0.313 & 0.313 \\
no. of observations & 1281 & 1281 & 1623 & 1623 & 2582 & 2582 \\
\hline \hline
\end{tabular}

Table A22 Impact of mobile phones on household selling prices: south, DiD-OLS,

\begin{tabular}{lcc|cc|cc}
\hline dependent variable: $\ln ($ selling price) & $(1)$ & $(2)$ & $(3)$ & $(4)$ & $(5)$ & $(6)$ \\
\hline mobile phone & -0.210 & $-0.215^{*}$ & -0.283 & -0.282 & $-0.243^{*}$ & $-0.243^{*}$ \\
& $(0.122)$ & $(0.114)$ & $(0.166)$ & $(0.165)$ & $(0.132)$ & $(0.136)$ \\
year x province (binary) & Yes & yes & yes & yes & yes & yes \\
primary sampling unit (binary) & Yes & yes & yes & yes & yes & yes \\
Covariates & No & yes & no & yes & no & yes \\
$\mathrm{R}^{2}$ & 0.499 & 0.505 & 0.435 & 0.441 & 0.450 & 0.452 \\
no. of observations & 666 & 666 & 802 & 802 & 1246 & 1246 \\
\hline \hline
\end{tabular}


Figure A1 Mozambique: markets and production areas

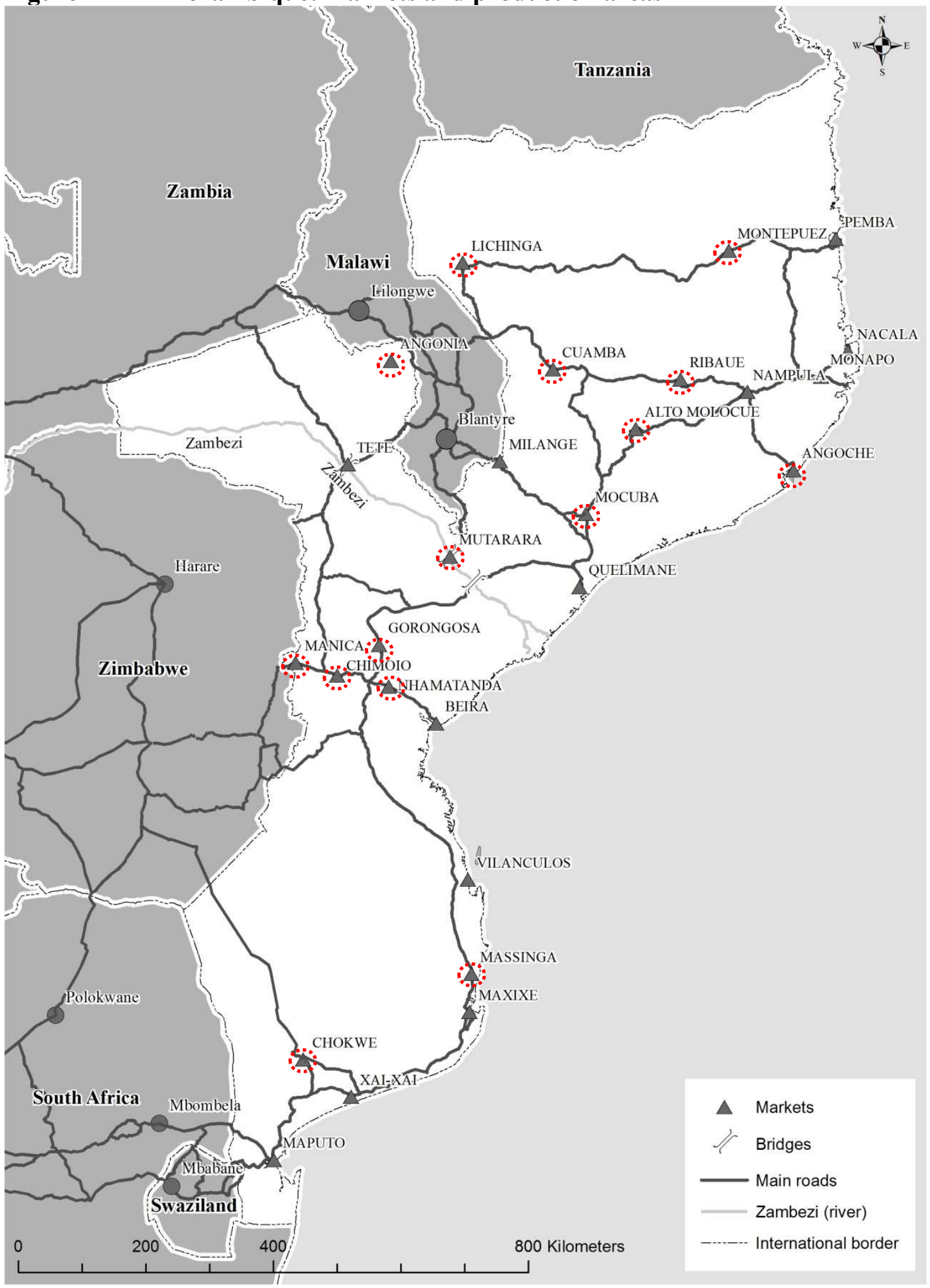

Source: VU SPINlab

Note: Producer markets for which SIMA producer prices are available are circled. 
Figure A2 Mozambique: rollout of network of mobile phone towers, 1998-2009
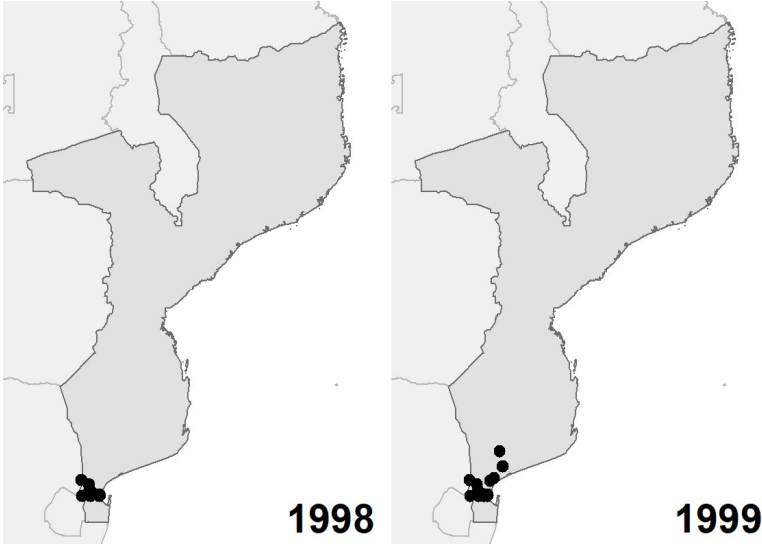

1999

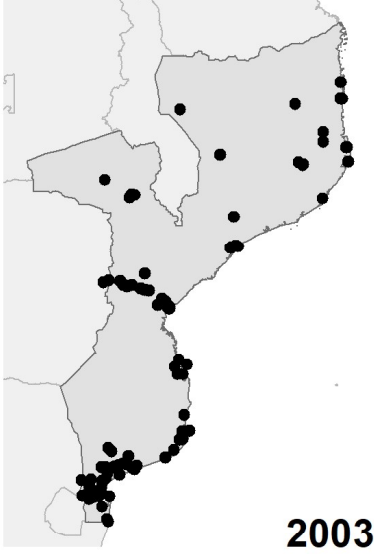

2002

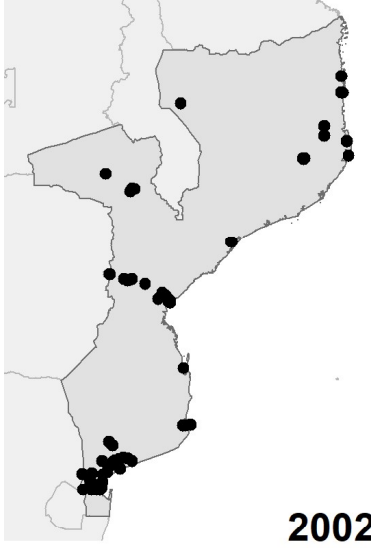

2003
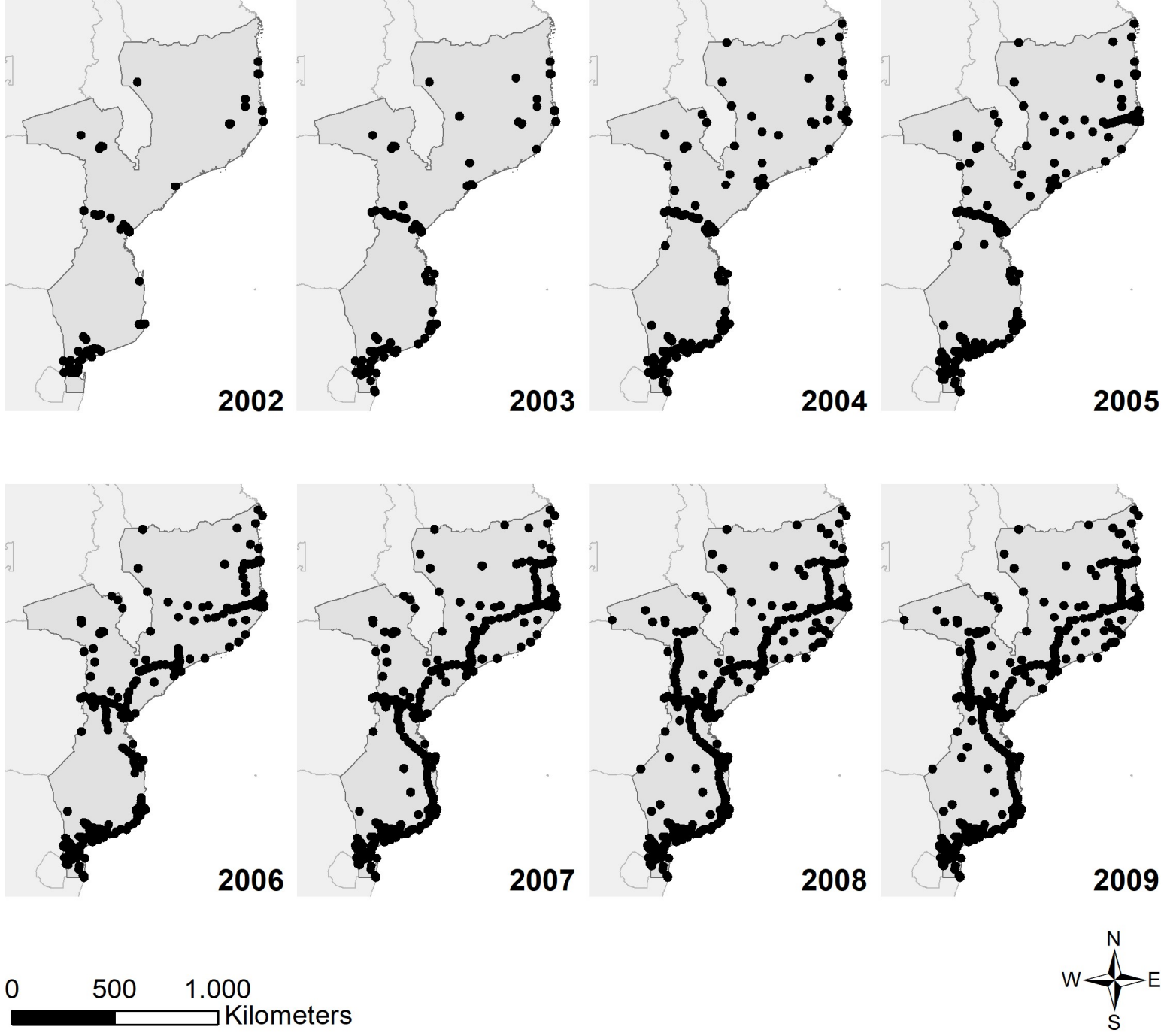

Source: VU SPINlab 
Figure A3 Population density, rainfall and maize production by province, 1999-2007

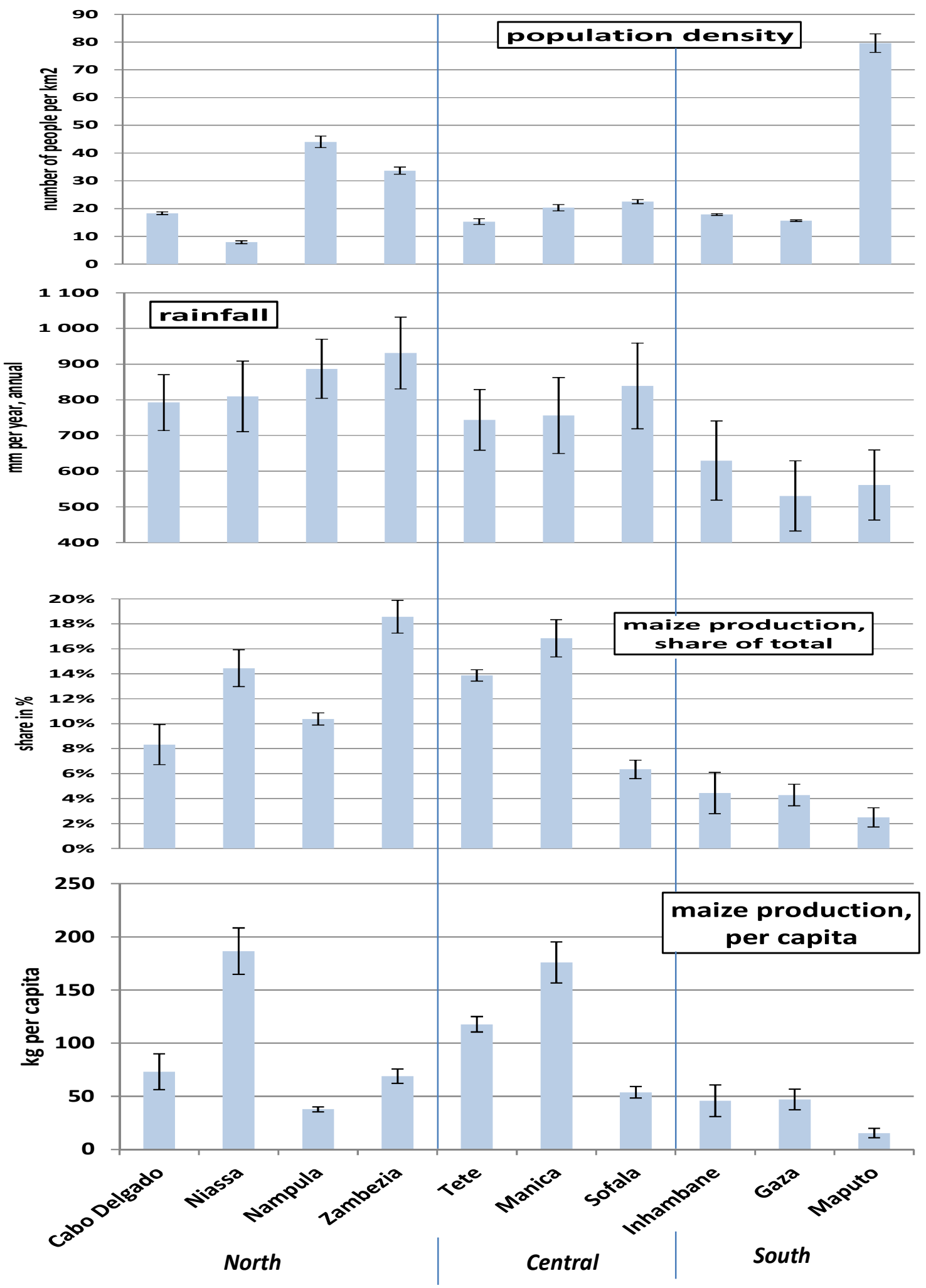

Source: (author's calculations based on data from) Instituto Nacional de Estatistica Moçambique, FEWSNET and Ministry of Agriculture, Early Warning Unit (Aviso Previo); The figure is based on aggregate (average) annual province data. Error bars show $95 \%$ confidence intervals. See the maps in this appendix for the location of provinces. 
Figure A4 Producer prices and market prices of maize

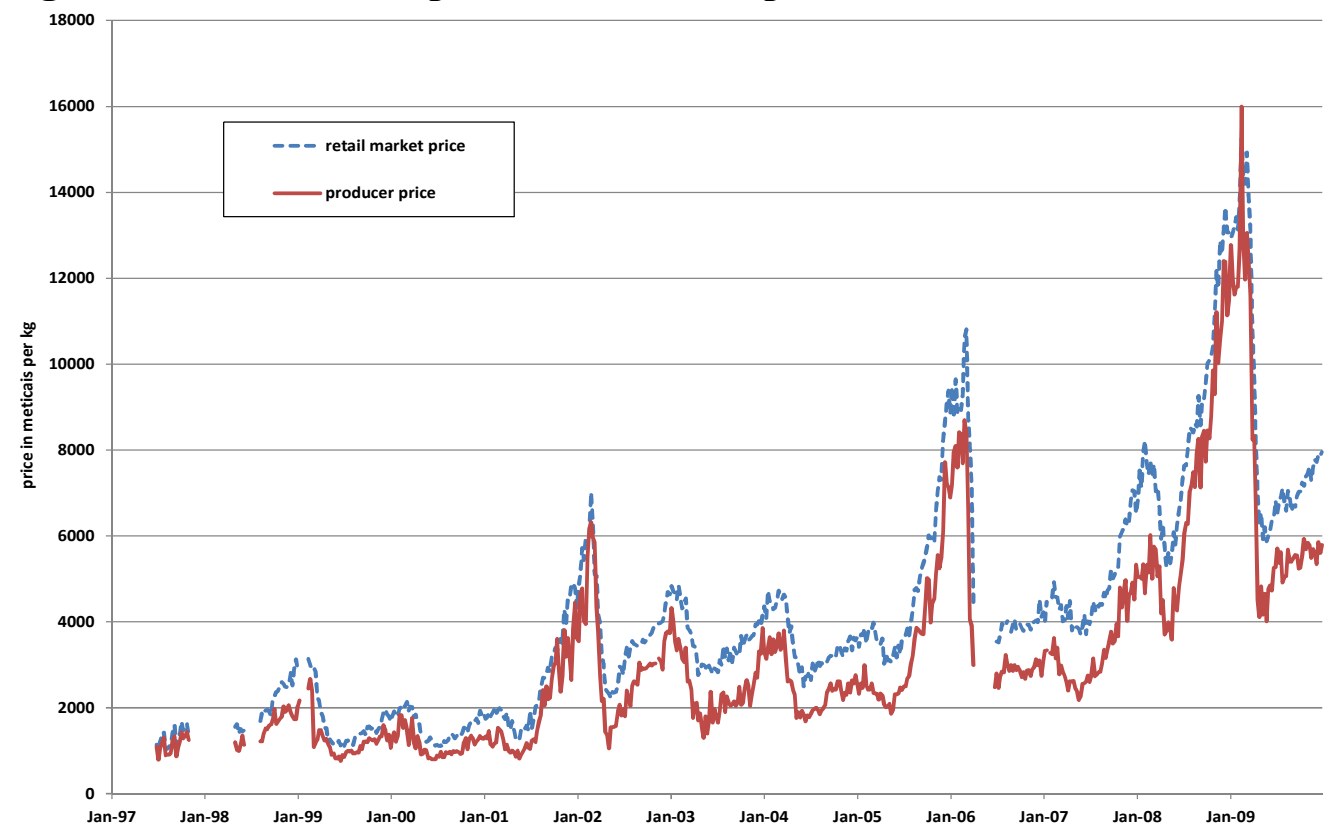

Source: Authors' calculations based on Sistema de Informação de Mercados Agrícolas de Moçambique data.

\section{Figure A5 Seasonality of Market Maize Prices by Market}

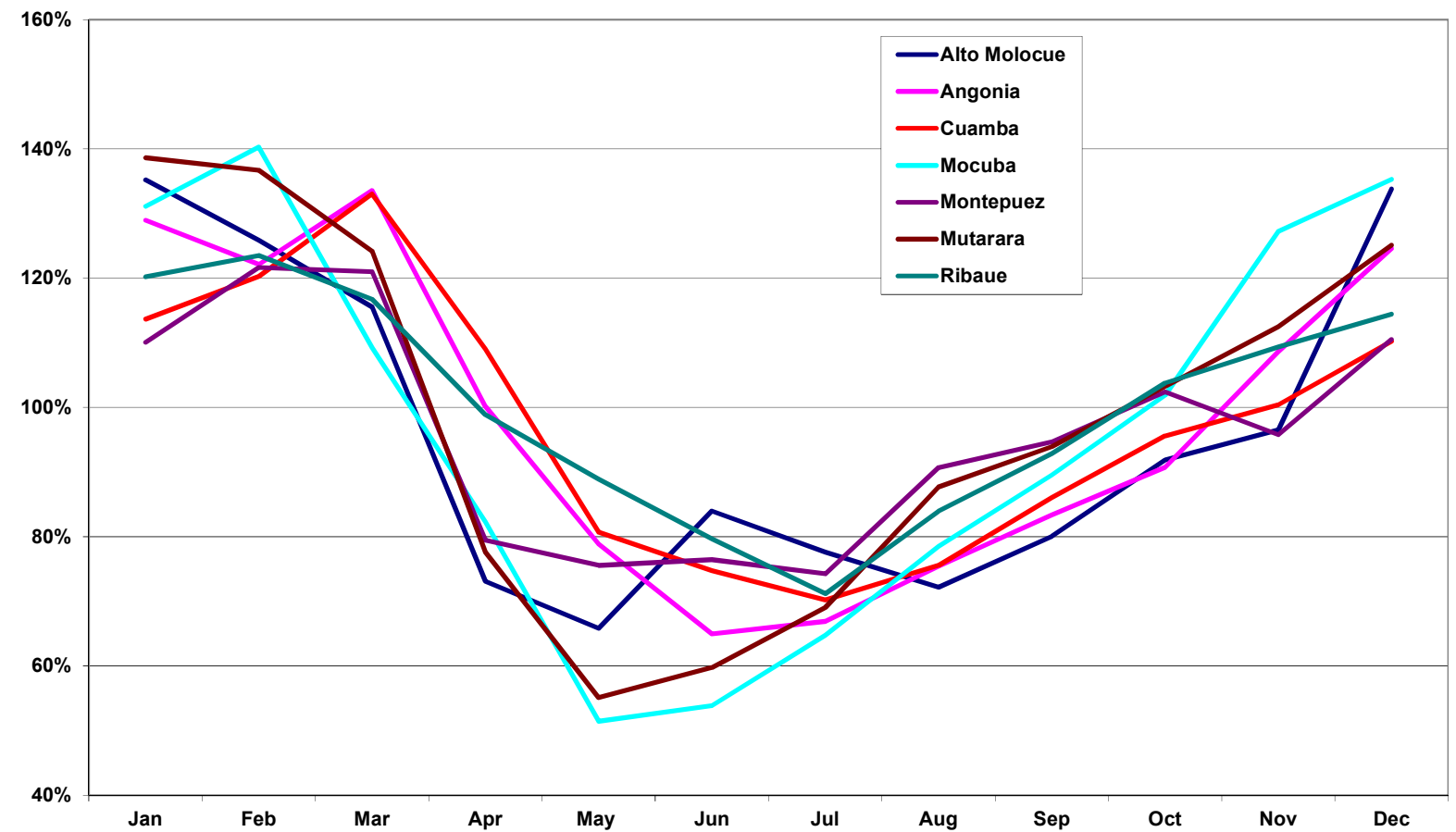

Note: The figure plots average monthly prices by market as a percentage of (centered) average annual prices in these markets, averaged over the years (1997-2009). It should be noted that averaging over the years disguises substantially larger seasonality that results from droughts. 
Figure A6 Margin between maize market prices and maize producer prices

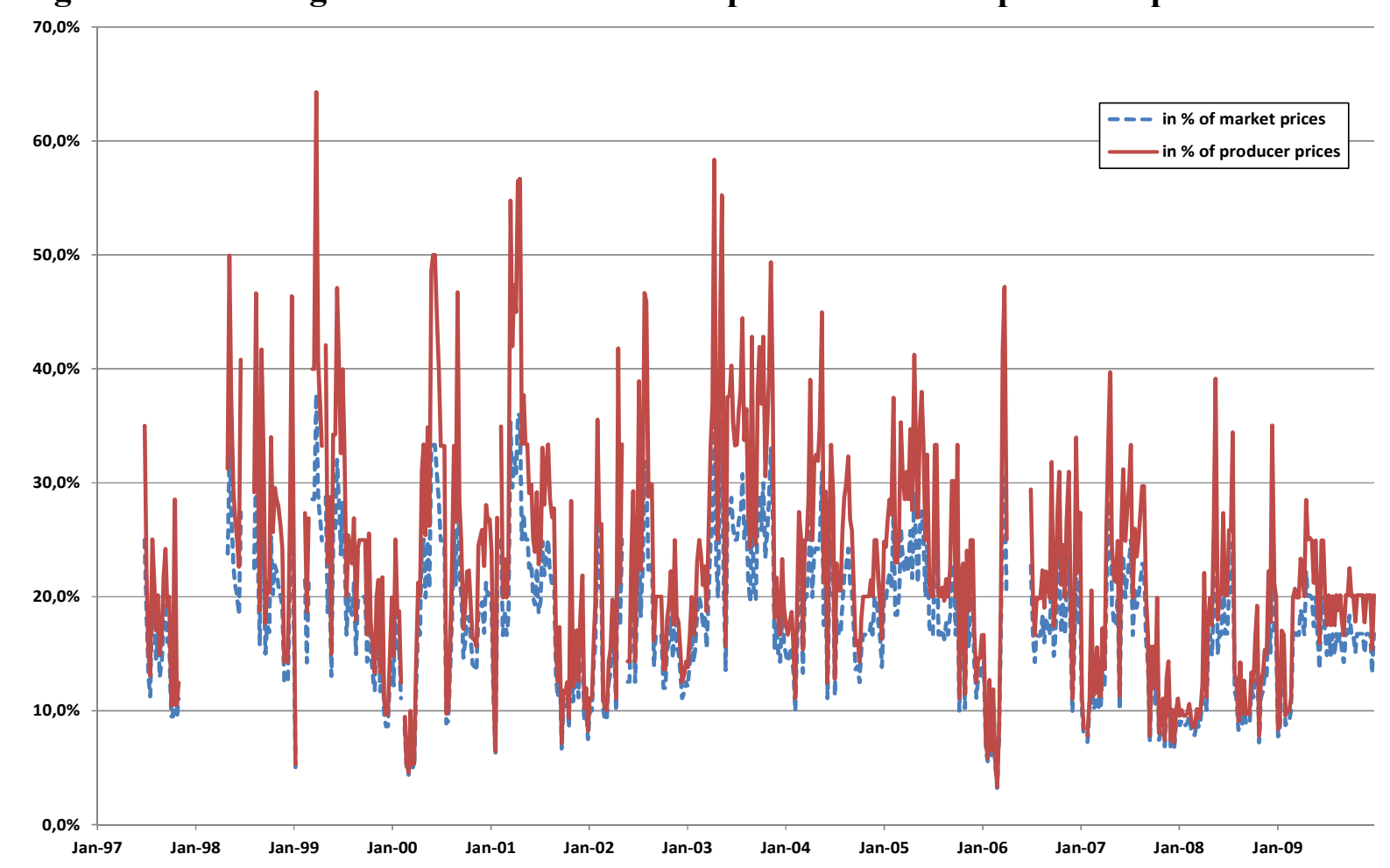

Source: Authors' calculations based on Sistema de Informação de Mercados Agrícolas de Moçambique data. Note: The figure shows the development over time of the margin (the market price minus producer price) expressed in percentage of either retail market or producer prices, and averaged over markets. Note that, due to missing observations, observations in the figure are averaged over different combinations of markets.

\section{Figure A7 Margins by markets}

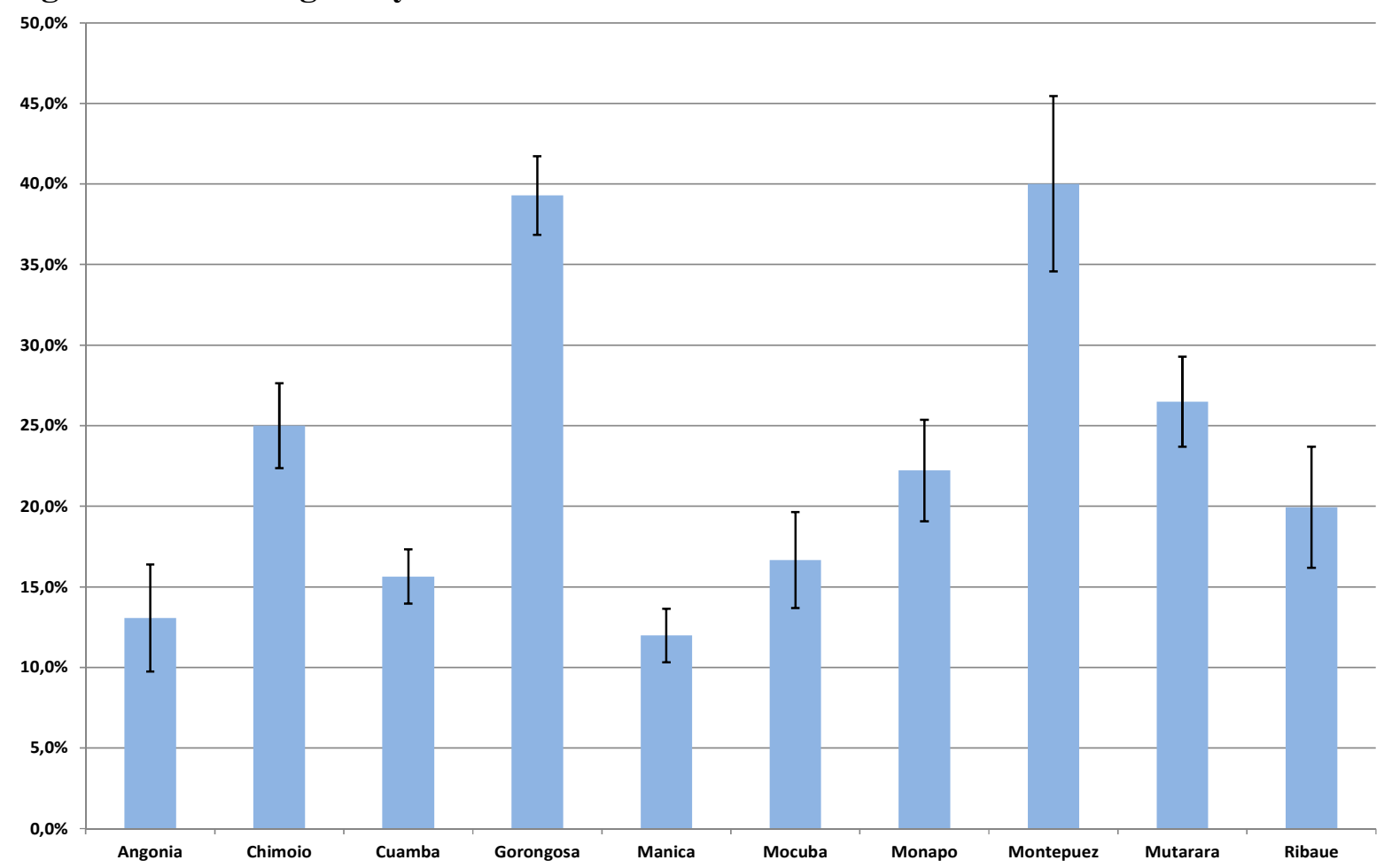

Source: Authors' calculations based on Sistema de Informação de Mercados Agrícolas de Moçambique data. (restricted to markets with more than 100 observations in the period from July 1997 to December 2009) 
Figure A8 Data availability by month (share in \% of total number of observations)
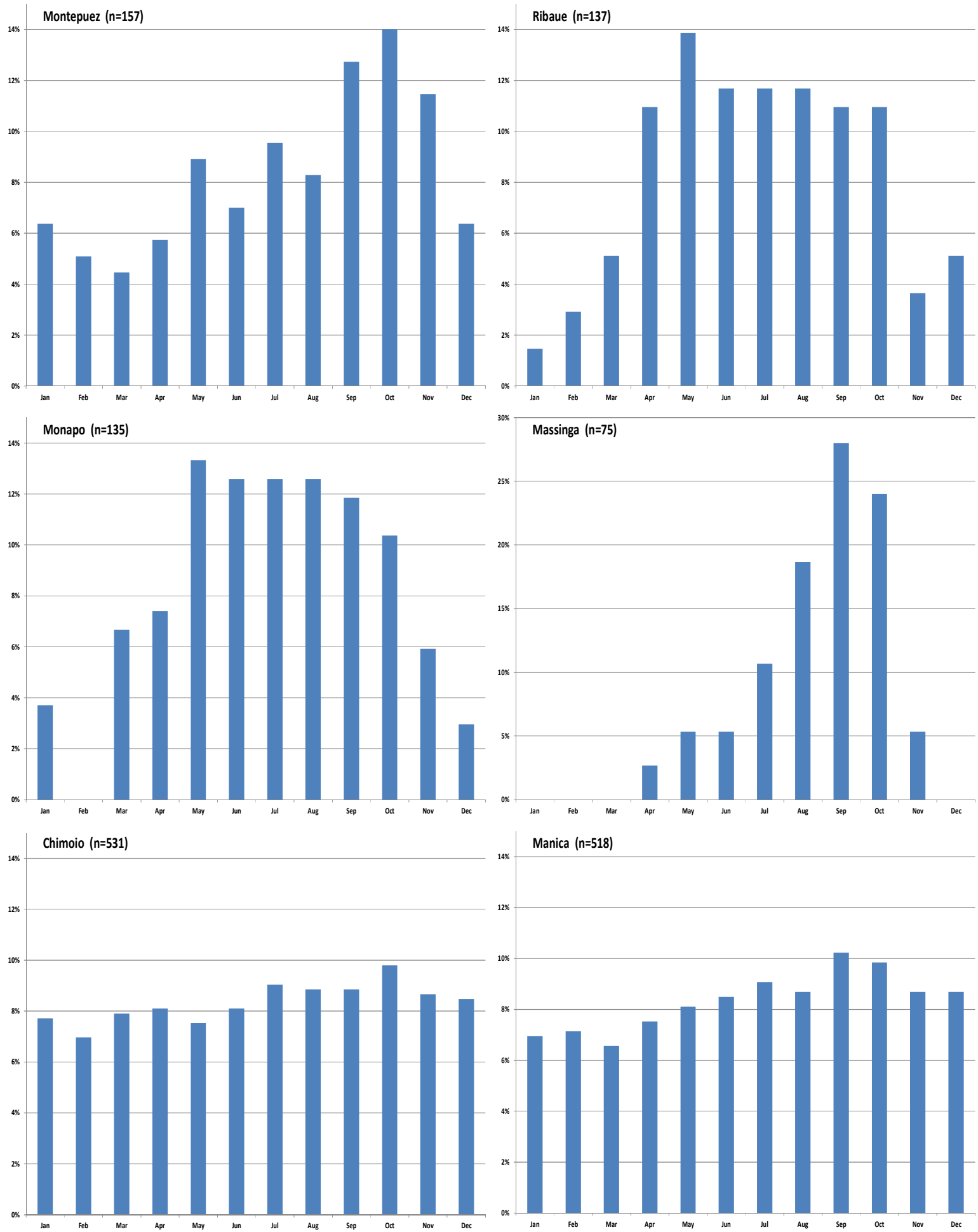
Figure A9 Seasonality in maize grain sales (sold when?)*

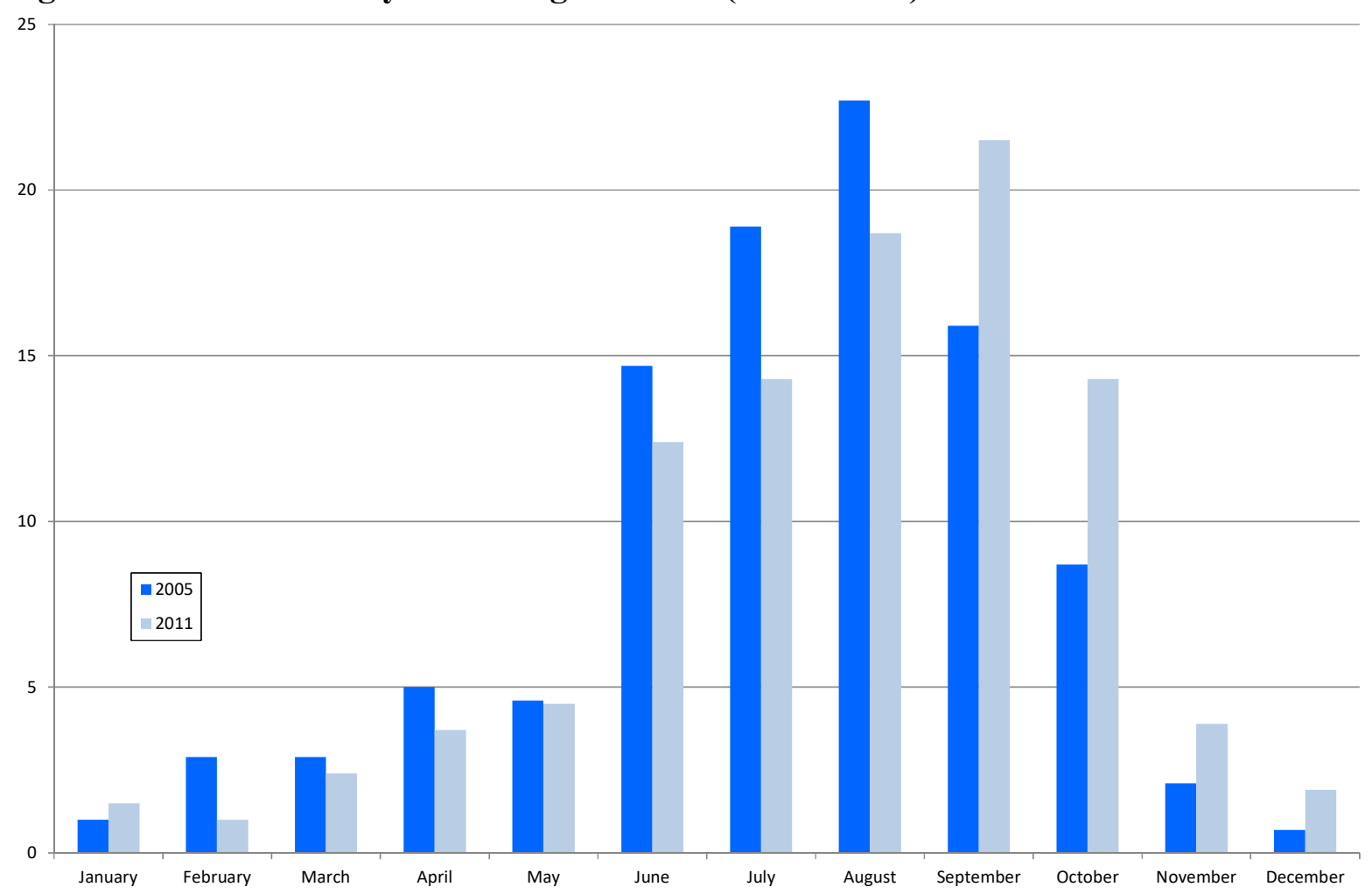

source: Trabalho de Inquérito Agrícola (TIA, various survey years)

* The TIA survey 2011 covers only 5 provinces (Nampula, Zambezia, Tete, Manica, Sofala). 


\section{Figure A10 TIA sales unit values and SIMA producer prices}
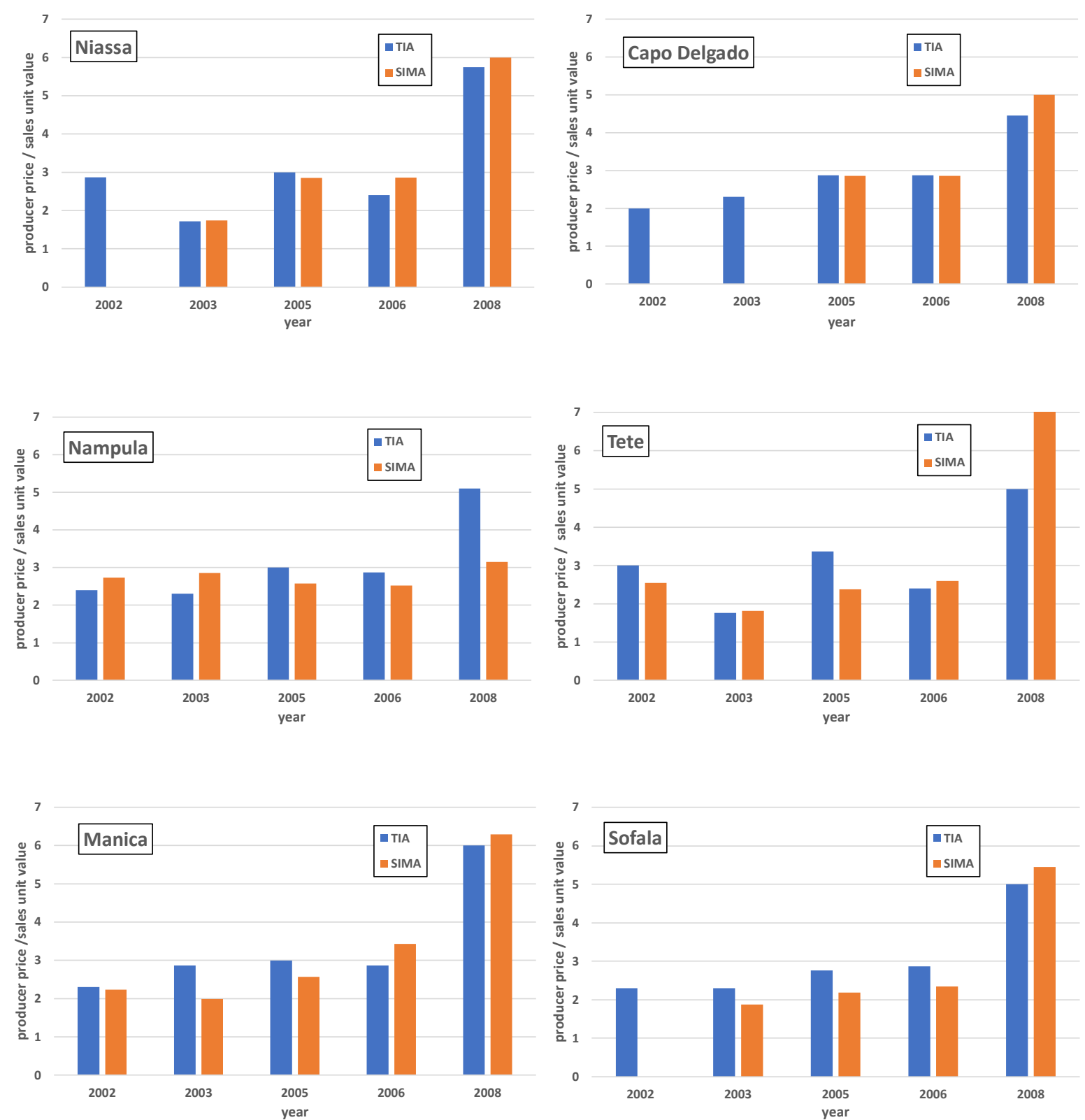

Source: calculations based on TIA household unit values and SIMA producer prices.

Note: SIMA producer prices are median producer prices, by year and by province, over all months except January, February, November and December; TIA sales unit values are median sales unit value by province and year, where the unit value is sales value divided by sales quantity. Sales in the TIA data are not dated: it is assumed that these take place during the 6 months after harvest, from May to October (see also Figure on seasonality in maize sales) 
Figure A11a Parallel trend test, annual data: impact of mobile phones on margins

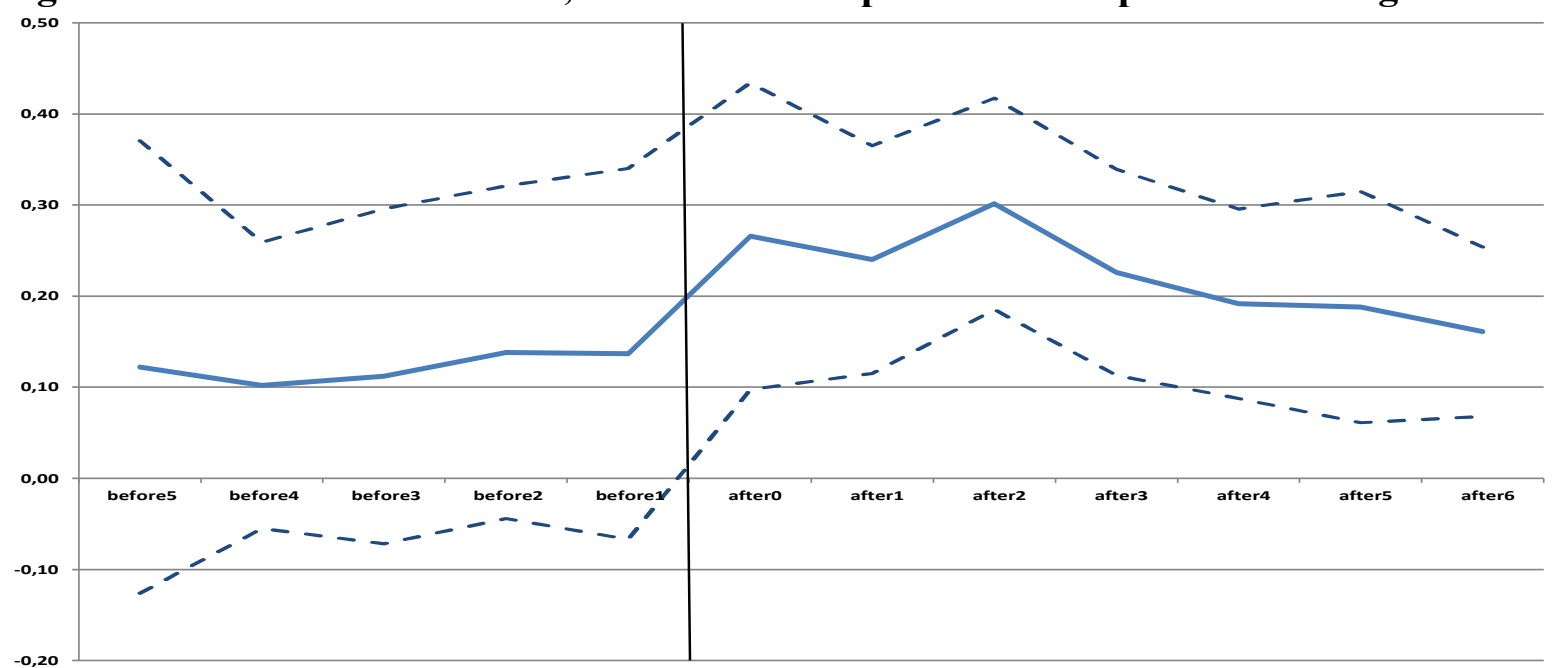

Figure A11b Parallel trend test, annual data: impact of mobile phones on producer prices

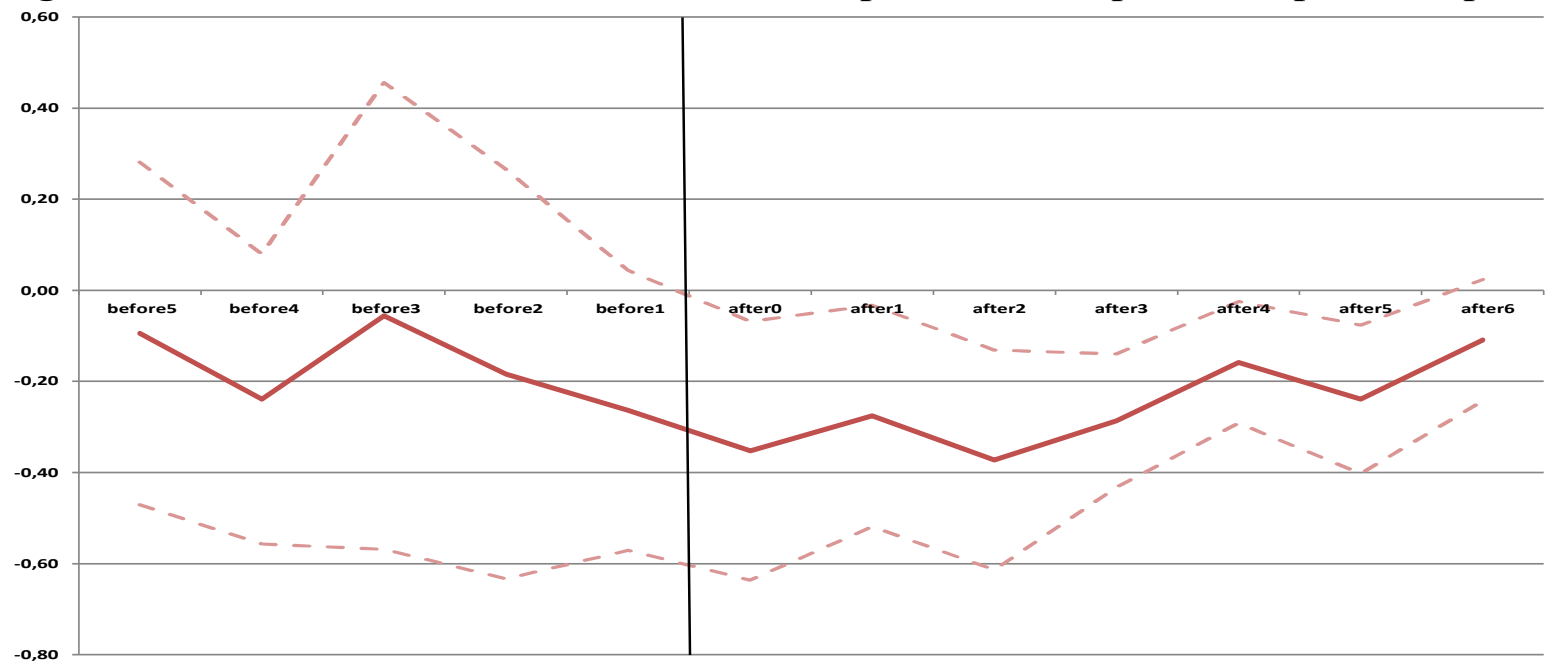

Figure A11c Parallel trend test, annual data: impact of mobile phones on market prices

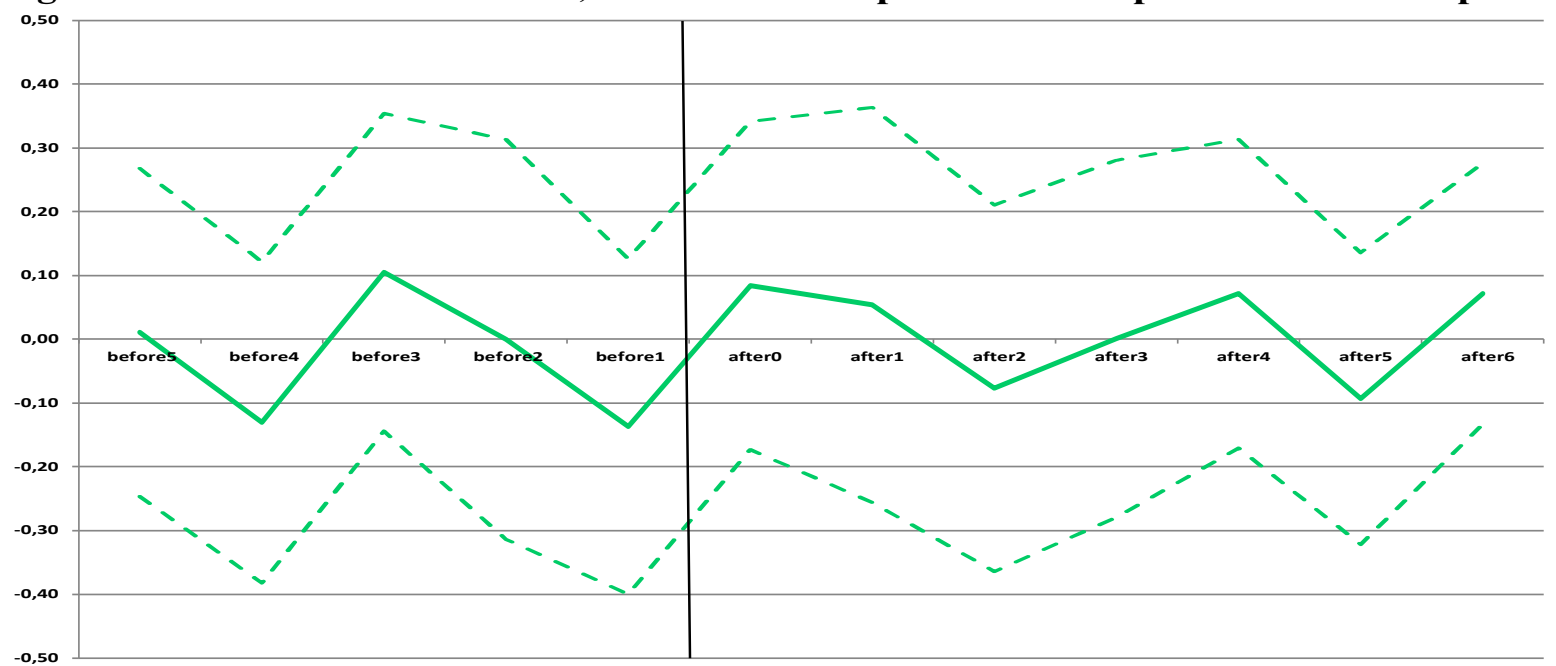

Note: dotted lines indicate $95 \%$ confidence intervals 
Figure A12a Distribution of weights in TWFE estimation: margins
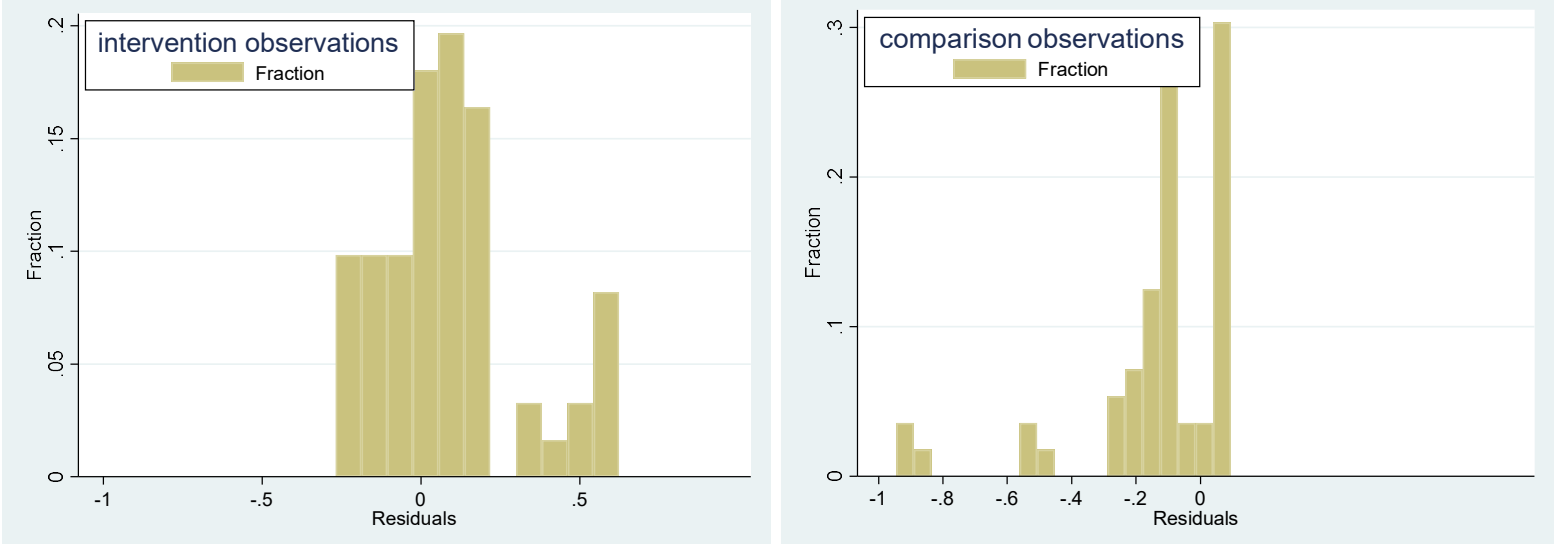

Figure A12b Distribution of weights in TWFE estimation: producer prices
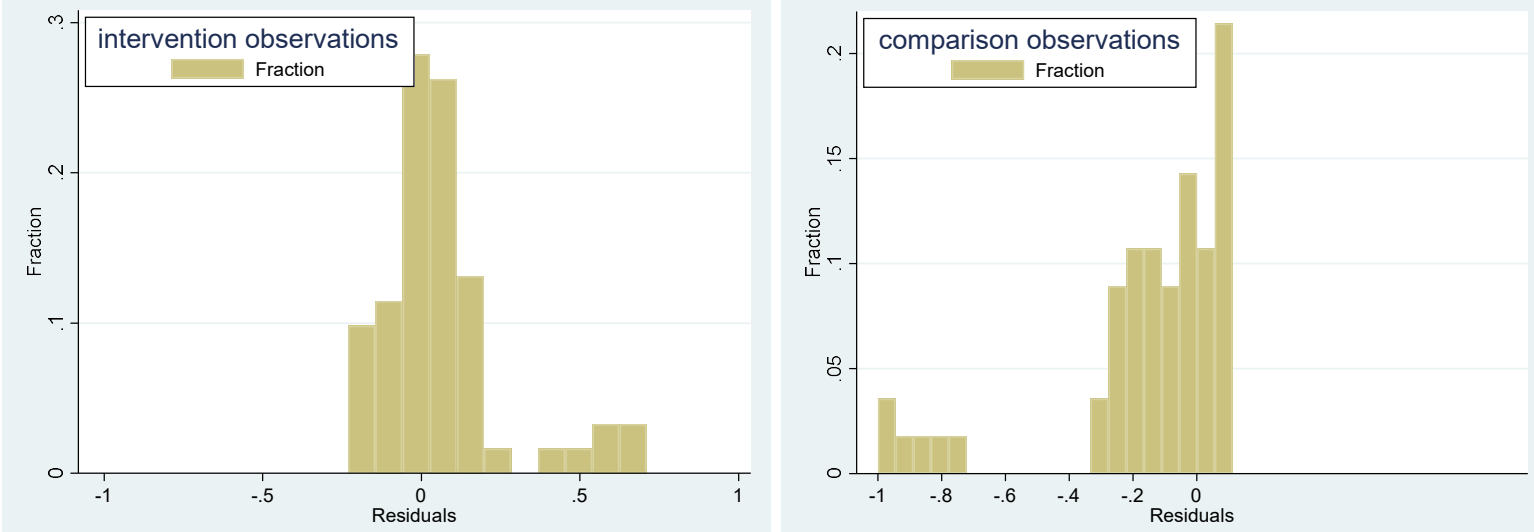

Note: The figures report the unscaled weights calculated as the residual of the estimation of the intervention on years and markets, and divided by intervention and comparison group (Jakiela, 2021). 
Figure A13a Robustness to omitting negative intervention weights: retaining a fixed number of post-intervention observations, margins

$\mathbf{0 , 3 0}$

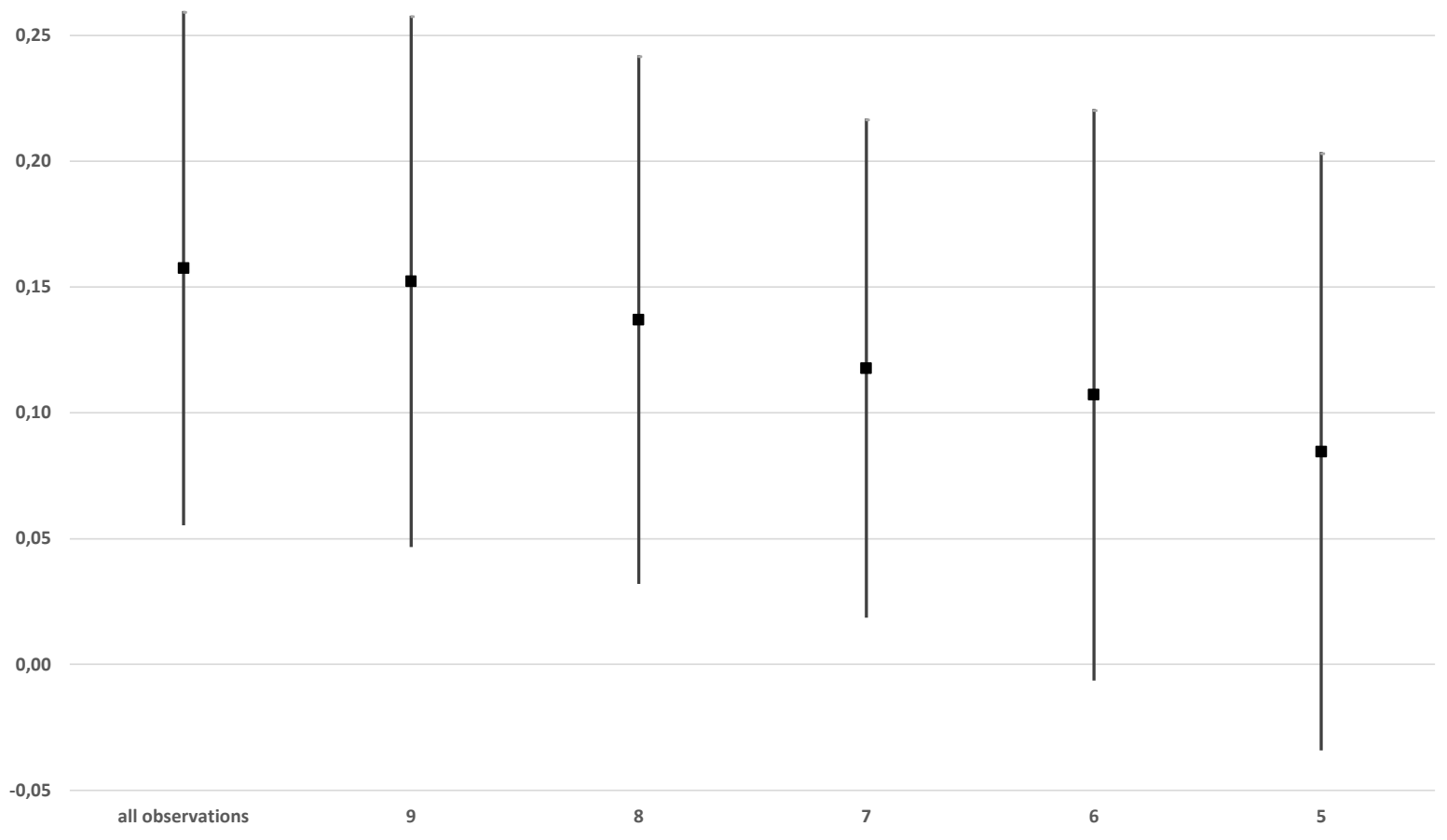

Figure A13b Robustness to omitting negative intervention weights: retaining a fixed number of post-intervention observations, producer prices

0,10

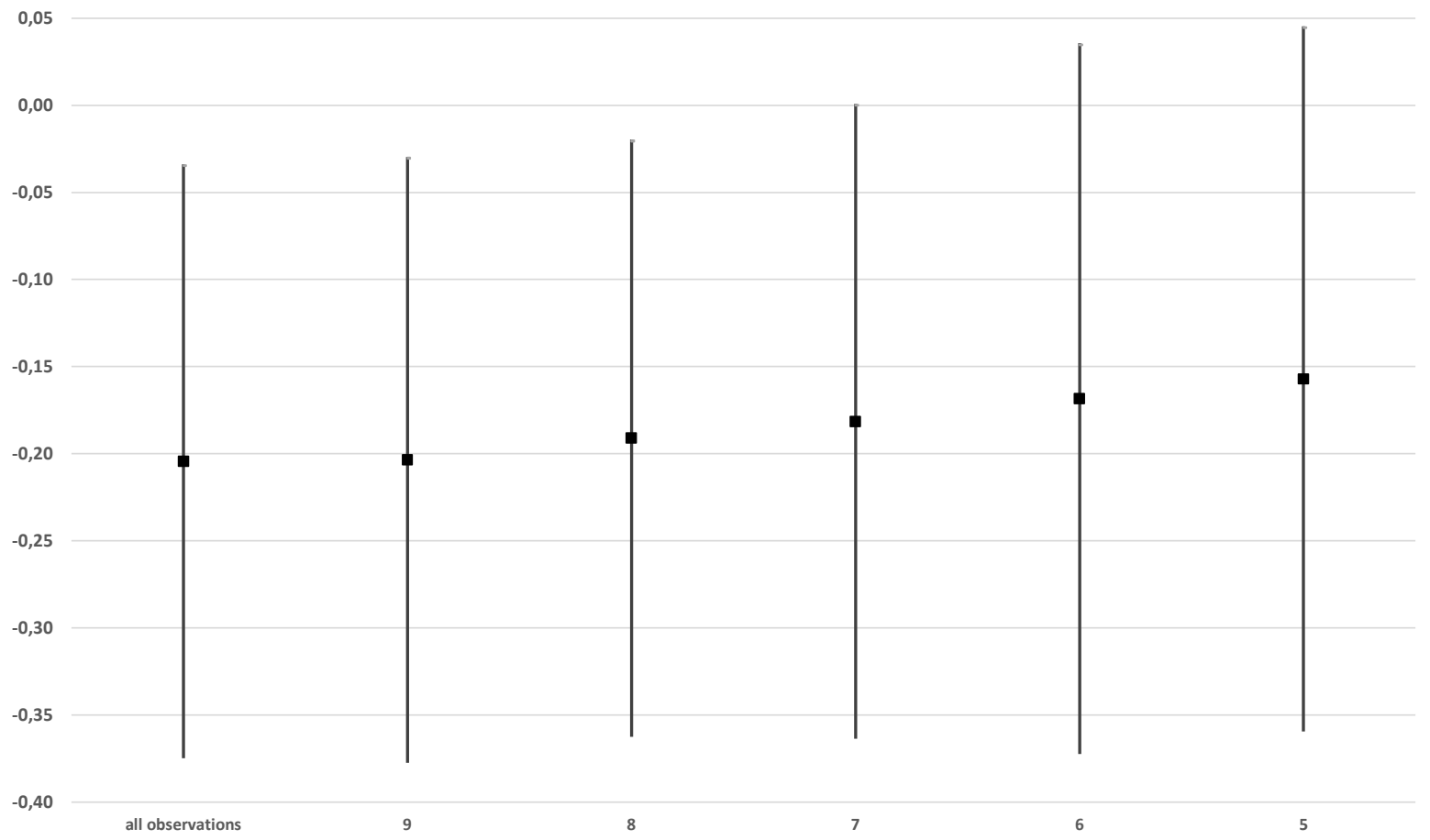

Note: The figures show estimated impact coefficients when retaining resp. 9 years of post-intervention observations, 8 years, etc., thereby omitting observations with negative intervention weights (Jakiela, 2021).

60 


\section{Figure A14 Distance from the nearest market of maize selling households with mobile coverage}

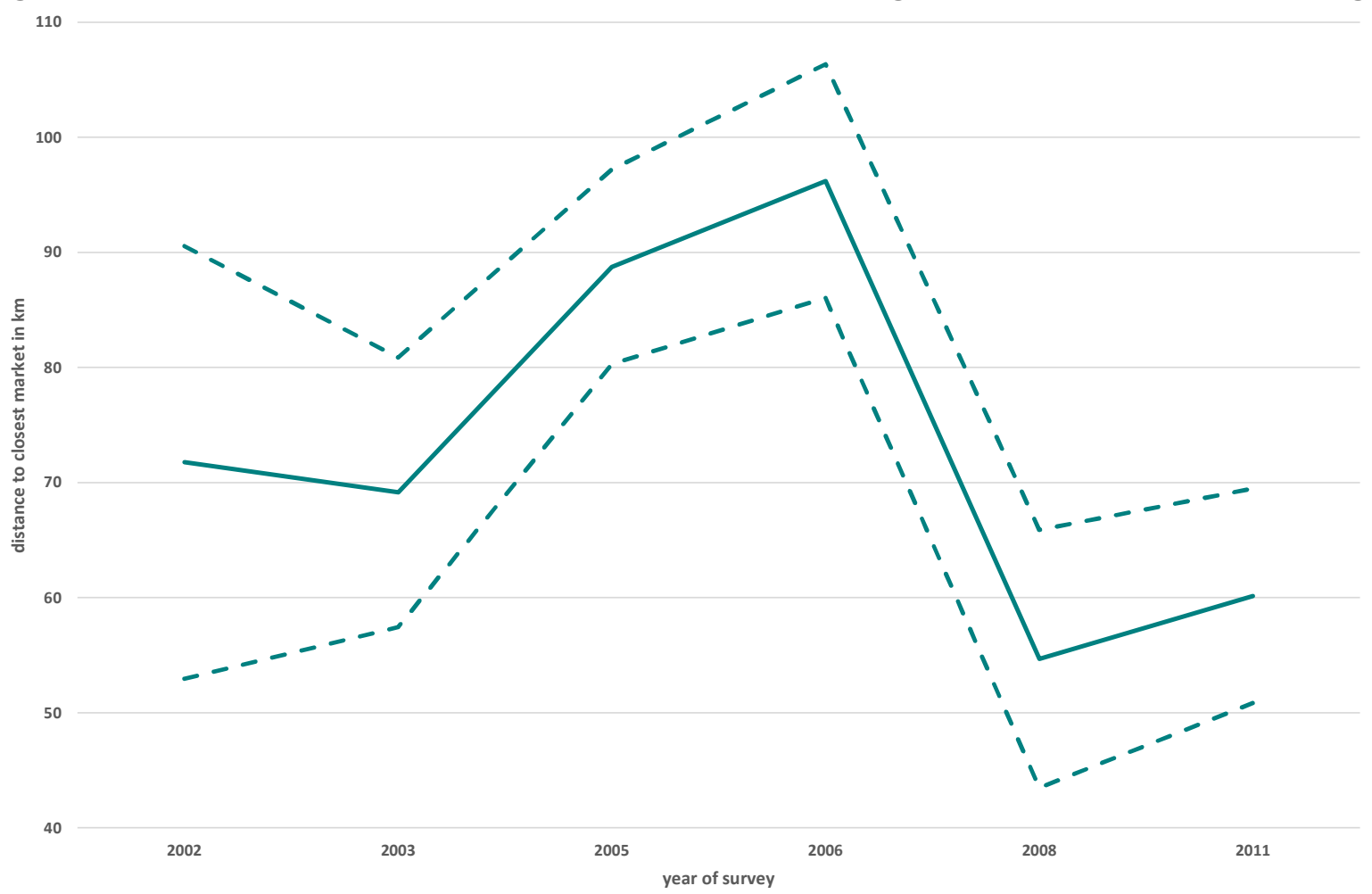

Note: The figure shows the average distance from the nearest market of households that sell maize and have mobile phone coverage. The drastic drop in 2008 reflects the aftermath of the 2007 flood. 